\title{
Myosin VI regulates ciliogenesis by promoting the turnover of the centrosomal/satellite protein OFD1
}

Elisa Magistrati ${ }^{*}$, Giorgia Maestrini ${ }^{1}$, Mariana Lince-Faria ${ }^{2}$, Galina Beznoussenko ${ }^{1}$, Alexandre Mironov $^{1}$, Elena Maspero ${ }^{1}$, Mónica Bettencourt-Dias ${ }^{2}$, Simona Polo $^{1,3 *}$

${ }^{1}$ IFOM, Fondazione Istituto FIRC di Oncologia Molecolare, Milan, Italy.

${ }^{2}$ IGC, Instituto Gulbenkian de Ciencia, Oeiras, Portugal.

${ }^{3}$ Dipartimento di Oncologia ed Emato-oncologia, Università degli Studi di Milano, Milan, Italy.

* Correspondence to:

E.M. (email: elisa.magistrati@ifom.eu) or S.P. (email: $\underline{\text { simona.polo@ifom.eu) }}$ 


\begin{abstract}
The actin motor protein myosin VI is a multivalent protein with diverse functions. Here, we identified and characterised a myosin VI ubiquitous interactor, the oral-facial-digital syndrome 1 (OFD1) protein, whose mutations cause malformations of the face, oral cavity, digits, and polycystic kidney disease. We found that myosin VI regulates the localisation of OFD1 at the centrioles and, as a consequence, the recruitment of the distal appendage protein cep164. Myosin VI depletion in non-tumoural cell lines causes an aberrant localisation of OFD1 along the centriolar walls, which is due to a reduction in the OFD1 mobile fraction. Finally, loss of myosin VI triggers a severe defect in ciliogenesis that could be causally linked to an impairment in the autophagic removal of OFD1 from satellites. Altogether, our results highlight an unprecedent layer of regulation of OFD1 and a pivotal role of myosin VI in coordinating the formation of the distal appendages and primary cilium with important implications for the genetic disorders known as ciliopathies.
\end{abstract}




\section{Introduction}

Primary cilia are sensory structures extending from the surface of mammalian cells, with a major role in several signalling pathways essential for growth and differentiation, such as the Hedgehog and the Wnt signalling pathways (Berbari et al. 2009; Malicki and Johnson 2017). The formation of the primary cilium is a highly regulated multi-step process that occurs in cells that exit the cell cycle and become quiescent. The primary cilium originates from the older centriole, called mother centriole, which docks to the plasma membrane and acts as basal body for the assembly of the microtubule ciliary axoneme (Sanchez and Dynlacht 2016). Impairment in the formation or function of the primary cilia leads to a variety of severe genetic syndromes, termed ciliopathies (Reiter and Leroux 2017). This group of disorders includes the oral-facial-digital (OFD) type I, the Simpson-Golabi-Behmel type 2 and the Joubert syndromes, which are caused by mutations in the OFD1 gene (Ferrante et al. 2006; Coene et al. 2009; Ferrante et al. 2001; Zullo et al. 2010; Field et al. 2012; Feather et al. 1997; Budny et al. 2006). The mechanisms underlying many of the disease phenotypes associated with ciliary dysfunction have yet to be fully elucidated. Dissecting the regulatory mechanisms of OFD1 has the potential to offer new therapeutic tools for the treatment of ciliopathies.

OFD1 is a protein component of the centrioles and pericentriolar satellites, and acts both as a positive and negative regulator of primary ciliogenesis (Ferrante et al. 2006; Tang et al. 2013; Morleo and Franco 2020). The localisation of OFD1 is differentially regulated depending on the cell compartment. At the centrioles, OFD1 is recruited to the distal tip through the interaction with the $\mathrm{C} 2$ domain containing 3 centriole elongation regulator $(\mathrm{C} 2 \mathrm{CD} 3)$, a protein required for centriole elongation (Thauvin-Robinet et al. 2014). OFD1 recruitment is under the control of a subset of centriole proteins that are present only in the daughter centriole (daughter centriolespecific proteins), but the molecular link is unknown (Wang et al. 2018). OFD1 in turn promotes the recruitment of the distal appendages, structures present on the distal side of the mother centriole. These structures are essential for the docking of the mother centriole to the cellular membrane and its conversion to basal body, required for ciliogenesis (Singla et al. 2010; Wang et al. 2018). Furthermore, OFD1 is required for the recruitment of IFT88, a protein essential for the assembly of the primary cilium (Singla et al. 2010). Despite the growing literature that explores 
the process of primary cilium formation, the mechanistic details of this sequential recruitment of C2CD3, OFD1 and distal appendages remain unclear.

OFD1 is also localised at the centriolar satellites, which are non-membrane electron-dense particles containing regulatory proteins of centrosomes and cilia (Lopes et al. 2011). This localisation depends on the trafficking protein particle complex subunit 8 (TRAPPC8), which mediates the interaction between OFD1 and the main structural component of the centriolar satellites, namely PCM1 (Zhang et al. 2020).

While the centriolar pool of OFD1 is rather stable, the satellite pool shows a higher turnover (Tang et al. 2013). Indeed, upon serum starvation, OFD1 is removed from the satellites by autophagy, and this process is required for ciliogenesis (Tang et al. 2013; Park et al. 2018). Interestingly, the depletion of OFD1 from the satellites is sufficient to induce ciliogenesis also in autophagyimpaired cells (Tang et al. 2013), indicating that OFD1 turnover at the satellites controls per se the formation of the primary cilium. Moreover, OFD1 appears to regulate autophagosome biogenesis in a feedback loop that aims at limiting autophagy activation (Morleo et al. 2020).

A proteomic study identified OFD1 as a possible interactor of myosin VI (O'Loughlin, Masters, and Buss 2018), a unique motor protein that moves towards the minus end of the actin filaments (Magistrati and Polo 2020). The molecular pathways and the physiological relevance of this interaction remain unknown. Here, we characterized the interaction between the two proteins and we investigated the role of myosin VI in OFD1 regulation. 


\section{Results}

\section{OFD1 interacts with both myosin VI isoforms}

The functional and phenotypic diversity associated with myosin VI arises from alternativelyspliced isoforms that interact with multiple proteins (Magistrati and Polo 2020). To capture common interactors, we used co-immunoprecipation assay and analysed by mass spectrometry the interactome of endogenous myosin VI in a set of cell lines of epithelial origin expressing the different isoforms at various level, namely MDA-MB-231, HeLa, MCF10A, and Caco-2 cells (Supplementary Table 1). 13 proteins were found in all four cell lines (Figure 1A) and most of them were identified as myosin VI interactors for the first time. We focused our attention on OFD1 and we validated the interaction between myosin VI and OFD1, using a second anti-myosin VI antibody (Figure 1B) and by performing a reverse co-immunoprecipitation experiment (Figure $1 C)$.

Since OFD1 is a centriolar protein, we assessed the localisation of myosin VI in this organelle. By immunofluorescence (Supplementary Figure 1A) and proximity ligation assay (PLA, Supplementary Figure 1B) we could demonstrate that myosin VI localises at centrioles in correspondence of OFD1 staining, suggesting that the interaction between the two proteins can occur at least at the level of the centrioles. To further confirm this idea, we performed immunogold electron microscopy analysis of the endogenous myosin VI. As expected, myosin VI shows multiple signals corresponding to the various cytoplasmatic organelles where it performs its function (Magistrati and Polo 2020). Notably, a specific signal was evident at the level of centriole walls in wild-type but not in a myosin VI knock-out (KO) cell line (Figure 1D).

Next, we examined in detail the interaction between myosin VI and OFD1. Through immunoprecipitation and pull-down experiments, we confirmed that the short and long myosin VI isoforms can equally bind OFD1 and that the binding is mediated by the tail domain of myosin VI (Supplementary Figure 2A, B). In an attempt to characterise the site of the interaction, we focused on the major, well-characterised myosin VI cargo binding sites, namely the WWY motif (Spudich et al. 2007), the RRL motif (Sahlender et al. 2005) and the MyUb (Myosin VI Ubiquitin-binding) domain (Penengo et al. 2006; He et al. 2016). Point mutations in key residues did not affect the binding to OFD1 (Supplementary Figure 2C, D), prompting us to look for another binding region inside the myosin VI tail. By structure-function analysis we identified the $\mathrm{C}$-terminal region that 
starts from the MyUb as critical, but not sufficient to reach the OFD1 binding level of the entire tail domain (Figure 1E). Interestingly, the SAH domain, while it does not interact with OFD1 per se (Supplementary Figure 2E), appears to be required for the maximum binding (Figure 1E), implying that the conformation of the tail may be important for the interaction (Magistrati and Polo 2020).

We then investigated the region of OFD1 that mediates myosin VI binding. Starting from the Nterminus, OFD1 is composed of a highly conserved Lis1 homology (LisH) motif that is important for protein-protein interactions, protein stability and intracellular localisation (Singla et al. 2010), followed by six coiled-coils that are important for centrosomal localisation (Romio et al. 2004; Lopes et al. 2011) and a C-terminal LIR domain that mediates the binding to the autophagosomes (Morleo et al. 2020). Pull-down experiments showed that OFD1 binds myosin VI through its coiled-coils region, while the LIR domain and the N-terminal region containing the LisH motif appear dispensable for the interaction (Figure 1F). Unfortunately, the bad behaviour of the shorter constructs of OFD1 precluded further analysis of the interaction boundaries, as well as possible crystallisation attempts.

\section{Myosin VI regulates OFD1 levels at the centrioles and distal appendage recruitment}

We next sought to determine the physiological role of myosin VI-OFD1 interaction by examining the effects of myosin VI depletion on centriole morphology and activity. To this end, we moved to retinal pigment epithelial (hTERT-RPE1) cells, diploid immortalised cells that maintain normal checkpoints on cell cycle progression and are commonly used for ciliogenesis assay. Initial characterisation of myosin VI knock-down (KD) RPE1 cells failed to detect major alterations in the structure of the centrioles, as evident by transmission electron microscopy (TEM) analysis (Supplementary Figure 3A). Both TEM and immunofluorescence analysis highlighted that the subcellular localisation of the centrosome, identified by pericentrin staining, is significantly altered upon myosin VI depletion, with an increased centrosome-plasma membrane distance in myosin VI KD cells (Supplementary Figure 3B).

Then, we focused on OFD1 behaviour at centrioles. OFD1 localisation is exquisitely limited to two specific pools - at the centrioles and at the centriolar satellites - that have different functions and regulations (Lopes et al. 2011; Tang et al. 2013; Wang et al. 2018). We first focused on the centriolar pool using the microtubules depolymerising drug nocodazole (Dammermann and 
Merdes 2002) to remove the satellites (Supplementary Figure 4A). To assess the amount of OFD1 at the centrioles, we calculated the fluorescence intensity at the centrioles' spots, identified by the anti-centrin1 staining. To avoid biases due to the different phases of centriole duplication, we considered only cells with two centrioles, one of which marked by the distal appendage protein cep164 (Figure 2A). Our analysis revealed that myosin VI depletion causes an accumulation of OFD1 signal both in the mother centriole, identified with cep164, and in the daughter cep164negative centriole (Figure 2B-C). Interestingly, the increase of OFD1 signal at the centrioles is not accompanied by a parallel increase of the protein level (Figure 2D), indicating a selective increased recruitment of OFD1 at the centrioles.

Previous studies demonstrated that OFD1 is required to constrain centriole elongation and to promote the recruitment of the distal appendages at the mother centriole (Wang et al. 2018; Singla et al. 2010). Confirming the aberrant accumulation of OFD1 at centrioles, we found that myosin VI depletion leads to an increased recruitment of the distal appendage protein cep164 at the mother centriole (Figure 2E-F). Moreover, the effect scored in myosin VI KD cells was rescued by the parallel depletion of OFD1, indicating that the cep164 accumulation is a secondary effect caused by OFD1 increase at centrioles (Figure 2E-F).

\section{Myosin VI depletion induces cell cycle arrest in non-tumoural cells through p53 activation}

While exploring the effects of myosin VI KD, we unexpectedly observed a severe proliferation impairment in myosin VI-depleted RPE1 cells (Figure 3A). Similar results were obtained with additional siRNA oligos (Supplementary Figure 5A-C) and in BJ-hTERT cells, another nontumoural cell line (Figure 3B). Analysis of the cell cycle by PI staining and FACS showed that myosin VI depletion induces an arrest in the G0/G1 phase, resulting in cellular senescence (Figure 3C-D). To investigate the cause of the cell cycle arrest, we performed immunoblot analysis and found that myosin VI-depleted cells display an increase in both p53 and p21 expression levels (Figure 3E). Consistently, double depletion of myosin VI and p53 by siRNA oligos rescues the proliferation of RPE1 cells (Figure 3F-G, Supplementary Figure 5A-C).

To clarify if the increase in OFD1 and cep164 recruitment to the centrioles upon myosin VI depletion may be due to p53 accumulation and cellular senescence, cells were treated with Nutlin3. This drug is a potent inhibitor of the p53 antagonist Mdm2 and induces p53 accumulation with consequent cell cycle arrest (Vassilev et al. 2004). After Nutlin-3 treatment, cells did not show any 
changes in the levels of OFD1 or cep164 at the centrioles (Figure 3H-J), confirming that the increased accumulation of OFD1 at centrioles we scored upon myosin VI depletion is specific to the lack of the myosin VI activity.

We then assessed if the activation of p53 upon myosin VI KD depends on defects occurring at centrioles. Indeed, alterations in the number or structure of the centrioles has been shown to cause cell cycle arrest, which is mediated by the activation of different pathways depending on the type of damage (Mikule et al. 2007; Ganem et al. 2014; Lambrus et al. 2016; Fong et al. 2016; Meitinger et al. 2016; Fava et al. 2017). To assess if the centrioles contribute to myosin VI depletion-induced p53 activation and cell cycle arrest, we sought to remove the centrioles from the cells and analyse cell proliferation. We used centrinone, a Plk4 inhibitor that blocks the formation of new centrioles (Wong et al. 2015), thus depleting them over a few cell cycles (Supplementary Figure 5D). To avoid the activation of p53 due essentially to centriole loss, we performed this experiment in 53BP1 KO RPE1 cells, in which p53 is not activated following centrinone treatment (Lambrus et al. 2016; Fong et al. 2016; Meitinger et al. 2016) (Supplementary Figure 5E). Strikingly, in centrinone-treated 53BP1 KO cells, myosin VI depletion caused p53 activation and cell cycle arrest similar to wild-type cells, as shown by Western blot and growth analysis (Supplementary Figure 5E, F).

Taken together, these results demonstrate that a p53-dependent cell cycle arrest occurs upon myosin VI depletion in non-tumoural cell lines, and that a general p53 activation does not induce OFD1 and Cep164 accumulation, as myosin VI KD does.

\section{Myosin VI controls the turnover of OFD1 at the centrioles}

Given the increased recruitment of OFD1 at the centrioles upon myosin VI depletion and the localisation of the motor protein at the centrioles, we hypothesised that myosin VI could have a direct impact on OFD1 at the centrioles. Through Structured illumination microscopy (SIM) superresolution microscopy, we confirmed the ring-like localisation of OFD1 at the distal tip of the mother and daughter centrioles in control cells (Wang et al. 2018). Conversely, we found that the lack of myosin VI caused an aberrant accumulation of OFD1 along the entire centriolar walls (Figure 4A).

This result prompted us to analyse the behaviour of OFD1 by fluorescence recovery after photobleaching (FRAP) to determine the turnover of the protein. Centrioles were identified with 
centrin1-dTomato (Figure 4B), while the satellite pool of OFD1 was eliminated with nocodazole treatment during the live cell imaging (Supplementary Figure 4B). While the speed of recovery was not affected, myosin VI depletion caused a significant decrease in the mobile fraction of OFD1, indicating the presence of a stable pool of OFD1 at the centrioles that cannot be mobilised (Figure 4C, D).

Collectively, these data indicate that in the absence of myosin VI, OFD1 cannot be removed from the centrioles and thus aberrantly accumulates at the centrioles.

\section{Myosin VI removes OFD1 from the satellites}

Besides the centrioles, OFD1 also localises at the centriolar satellites in cycling cells. Previous studies showed that serum starvation induces OFD1 removal from the satellites by autophagy, a process that is required for primary ciliogenesis (Tang et al. 2013; Morleo et al. 2020). Interestingly, myosin VI is a known regulator of autophagy, being essential for autophagosomelysosome fusion during autophagosome maturation (Tumbarello et al. 2012). To determine if myosin VI exerts a role on satellites, we first examined the effect of myosin VI depletion using the satellite marker PCM1, which is virtually absent at the centrioles (Dammermann and Merdes 2002). Although we could observe a strong reduction of PCM1 intensity around centrioles in myosin VI KD cells (Figure 5A and B), cells treated with Nutlin-3 showed a similar decrease (Figure 5C), suggesting that the p53 activation induced by myosin VI KD causes satellites loss. Consistently, myosin VI depletion does not affect PCM1 intensity in RPE1 p53 KO cells (Figure 5D).

Based on these results, we used RPE1 p53 KO cells to analyse the effect of myosin VI depletion on the satellite pool of OFD1. To eliminate the contribution of the centriolar pool of OFD1, we identified the satellites via PCM1 staining and calculated OFD1 intensity only in the area covered by PCM1 (Figure 6A). As previously shown (Tang et al. 2013; Akhshi and Trimble 2021), serum starvation induces the removal of OFD1 from the satellites. We could observe that this event is significantly impaired by the parallel depletion of myosin VI (Figure 6B). While serum starvation induces a decrease in OFD1 total protein levels (Akhshi and Trimble 2021; Morleo et al. 2020), the same effect is weaker in myosin VI-depleted cells (Figure 6C).

Ciliogenesis in tissue culture is mainly initiated by serum starvation, which arrests the cell cycle and triggers autophagy (Tang et al. 2013; Morleo et al. 2020). Our data support the idea that myosin 
VI contributes to OFD1 degradation induced by serum starvation. Thus, we examined the formation of primary cilia in myosin VI-depleted cells. To avoid confounding effect due to the cell cycle arrest induced by myosin VI depletion, we performed the experiment in RPE p53 KO cells. Remarkably, while around $30 \%$ of the p53 KO cells were found ciliated after starvation even in the absence of G1 arrest, myosin VI-depleted cells completely failed to form cilia (Figure 6D). These data imply a requirement of myosin VI activity for primary cilium formation. 


\section{Discussion}

Here, we identified and characterised a novel myosin VI interactor, OFD1, whose turnover is modulated by myosin VI both at the centrioles and at the centriolar satellites. Myosin VI activity on OFD1 appears to be critical for maintaining the correct amount of the distal appendages at the mother centriole and for the removal of OFD1 from the centriolar satellites to promote primary ciliogenesis. Thus, OFD1 can be added to the list of specialised cargo-adaptor proteins that link myosin VI to distinct cellular compartments and processes (Magistrati and Polo 2020). Importantly, both myosin VI short and long isoforms (Wollscheid et al. 2016) interact with OFD1, indicating that this functional interaction is conserved in all cells and is maintained upon epithelial cell polarisation where a switch between isoforms was observed (Biancospino et al. 2019; Buss et al. 2001)

At the centrioles, OFD1 localisation is restricted to the distal tip (Figure 4A) (Tang et al. 2013). Our FRAP analysis determined that the $45 \%$ of OFD1 present at the centrioles is mobile and rapidly exchanges with the cytoplasmic pool. In the absence of myosin VI, this fraction is reduced, allowing accumulation of OFD1 on the entire microtubule wall. At present, the mechanism by which myosin VI controls OFD1 turnover remains unclear. Since the speed of recovery is not affected ( $t_{1 / 2}$ in FRAP analysis, Figure 4D), it is conceivable that myosin VI is needed for shortrange transport and may exploit the actin filaments that are nucleated by the centrosome to promote the turnover of OFD1 via its motor activity. In this context, it is noteworthy that the SAH domain involved in myosin VI dimerisation and required for the movement (Mukherjea et al. 2014) is critical for the interaction between the two proteins (Figure 1E). At the distal tip, OFD1 could be stabilised by other proteins like C2CD3 (Thauvin-Robinet et al. 2014) that protect this centriolar protein from myosin VI-mediated removal.

Recent studies have highlighted a synergistic interplay between actin and microtubule dynamics in several cellular compartments. Actin-microtubule crosstalk is functionally relevant for mitotic spindle positioning (Farina et al. 2019; Inoue et al. 2019) or for cell shape and polarity during cell migration, and many proteins that mediate actin-microtubule interactions have already been identified (Dogterom and Koenderink 2019). Our data raise the possibility that myosin VI is one of these critical modulators at the centrosomes where it could exploit the actin-based network surrounding the centrosomes and the microtubule interactors that we have identified with the proteomic approach (i.e. Numa, Supplementary Table 1). Further investigations are needed to 
uncover the functional implications of this intriguing hypothesis that is supported by the recent identification of a Gai-LGN-NuMA-dynein axis activated upon Shh-Smo induction to promote ciliogenesis (Akhshi and Trimble 2021), and which is consistent with the aberrant positioning of the centrosomes observed in the absence of myosin VI (Supplementary Fig. 3B).

Our study also unveils an unprecedent phenotype of cell-cycle arrest and senescence following myosin VI depletion in p53-proficient cells. This effect was not evident in cancer cell lines, suggesting that myosin VI contributes to a pathway that sustains proliferation and maintains the cell cycle in check, and that becomes deregulated during carcinogenesis. While this possibility is currently under investigation, the cause of this phenotype is certainly unrelated to centriolar biology as demonstrated by the centrinone experiment (Supplementary Figure 5B,C). Another surprising finding of our study is that p53 activation is responsible for the satellite dispersion occurring upon myosin VI depletion, which was established by Nutlin-3 treatment that phenocopies myosin VI depletion, as well as by the rescue of the phenotype obtained in p53 KO cells. Thus, our study highlights a new intriguing function of p53 at satellites. Determination of how p53 senses the lack of myosin VI is an important area of future work that is predicted to shed light also on this phenotype.

Finally, our study identified for the first time myosin VI as a critical regulator of ciliogenesis. Based on its role in other cellular compartments, it is possible that myosin VI may act as an actin anchor for the basal body, by docking the mother centriole at the plasma membrane, or as an actinbased motor contributing to the trafficking towards the ciliary pocket (Akhshi and Trimble 2021). Nonetheless, our evidence suggests that myosin VI depletion affects autophagy-mediated removal of OFD1 from the satellites, a prerequisite for ciliogenesis (Akhshi and Trimble 2021; Morleo et al. 2020; Tang et al. 2013). Several findings link myosin VI to autophagy and autophagy receptors (Magistrati and Polo 2020; Tumbarello et al. 2012), and emerging evidence suggests that autophagy and ciliogenesis influence each other (Morleo and Franco 2019; Pampliega and Cuervo 2016). Mechanistically, myosin VI has been shown to act at the damaged mitochondria where it mediates their engulfment and clearance via the formation of F-actin cages (Kruppa and Buss 2018). The interaction with OFD1 suggests that myosin VI may be directly involved in the first phases of the autophagosome formation, although implication of F-actin cages cannot be excluded. Whatever the case, the identification of myosin VI as OFD1 regulator has important implications 
bioRxiv preprint doi: https://doi.org/10.1101/2021.06.18.448975; this version posted June 19, 2021. The copyright holder for this preprint (which was not certified by peer review) is the author/funder. All rights reserved. No reuse allowed without permission.

for a variety of ciliopathy syndromes in which OFD1 mutations compromise ciliogenesis (Singla et al. 2010). 


\section{Data availability}

The mass spectrometry raw datasets were deposited in PRIDE database and can be accessed through ProteomeXchange with the following Project Name: Pulldown CG42797 vs S2 cell lysate and Project accession: PXD026697. Full list of the specific interactors is provided in Supplementary Table 1.

\section{Acknowledgements}

We thank Brunella Franco for DNA constructs, Francesca Farina and Luca Fava for the generation of cell lines. We thank Paolo Soffientini, Angela Cattaneo, Massimiliano Garrè and Emanuele Martini at Cogentech facilities (Milan, Italy) for support in mass spectrometry and FRAP analysis. We are grateful to Wessen Maruwge for English language editing. This work was supported by the Associazione Italiana per Ricerca sul Cancro, (Investigator grant 2017- 19875 to S.P.). Elisa Magistrati's work is supported by the Associazione Italiana per la Ricerca sul Cancro. E.Mag. was and G.S. is a PhD student at the European School of Molecular Medicine (SEMM).

\section{Author Contributions}

Conceptualisation: E.Mag, and S.P; E.Mag, performed all the experiments with the help of G.M. and E.Mas.; M.L.F. aided in the imaging acquisition and SIM experiments; G.B. and A.M performed the EM experiment; M.B.D contributed to the planning and interpretation of data; S.P. coordinated the team, designed and supervised the project; E.Mag. and S.P. wrote the paper with contributions from all authors.

\section{Conflict of Interest statement}

The authors declare no competing interests. 


\section{References}

Akhshi, T., and W. S. Trimble. 2021. 'A non-canonical Hedgehog pathway initiates ciliogenesis and autophagy', The Journal of cell biology, 220.

Berbari, N. F., A. K. O'Connor, C. J. Haycraft, and B. K. Yoder. 2009. 'The primary cilium as a complex signaling center', Curr Biol, 19: R526-35.

Beznoussenko, G. V., and A. A. Mironov. 2015. 'Correlative video-light-electron microscopy of mobile organelles', Methods Mol Biol, 1270: 321-46.

Biancospino, M., G. R. Buel, C. A. Nino, E. Maspero, R. Scotto di Perrotolo, A. Raimondi, L. Redlingshofer, J. Weber, F. M. Brodsky, K. J. Walters, and S. Polo. 2019. 'Clathrin light chain A drives selective myosin VI recruitment to clathrin-coated pits under membrane tension', Nat Commun, 10: 4974.

Budny, B., W. Chen, H. Omran, M. Fliegauf, A. Tzschach, M. Wisniewska, L. R. Jensen, M. Raynaud, S. A. Shoichet, M. Badura, S. Lenzner, A. Latos-Bielenska, and H. H. Ropers. 2006. 'A novel X-linked recessive mental retardation syndrome comprising macrocephaly and ciliary dysfunction is allelic to oral-facial-digital type I syndrome', Hum Genet, 120: 171-8.

Burigotto, M., A. Mattivi, D. Migliorati, G. Magnani, C. Valentini, M. Roccuzzo, M. Offterdinger, M. Pizzato, A. Schmidt, A. Villunger, S. Maffini, and L. L. Fava. 2021. 'Centriolar distal appendages activate the centrosomePIDDosome-p53 signalling axis via ANKRD26', EMBO J, 40: e104844.

Buss, Folma, Susan D.Arden, Margaret Lindsay, J.Paul Luzio, and John Kendrick-Jones. 2001. 'Myosin VI isoform localized to clathrin-coated vesicles with a role in clathrin-mediated endocytosis', The EMBO Journal 14: 367684.

Coene, K. L., R. Roepman, D. Doherty, B. Afroze, H. Y. Kroes, S. J. Letteboer, L. H. Ngu, B. Budny, E. van Wijk, N. T. Gorden, M. Azhimi, C. Thauvin-Robinet, J. A. Veltman, M. Boink, T. Kleefstra, F. P. Cremers, H. van Bokhoven, and A. P. de Brouwer. 2009. 'OFD1 is mutated in X-linked Joubert syndrome and interacts with LCA5-encoded lebercilin', Am J Hum Genet, 85: 465-81.

Dammermann, A., and A. Merdes. 2002. 'Assembly of centrosomal proteins and microtubule organization depends on PCM-1', The Journal of cell biology, 159: 255-66.

Dogterom, M., and G. H. Koenderink. 2019. 'Actin-microtubule crosstalk in cell biology', Nat Rev Mol Cell Biol, 20: 38-54.

Farina, F., J. Gaillard, C. Guerin, Y. Coute, J. Sillibourne, L. Blanchoin, and M. Thery. 2016. 'The centrosome is an actin-organizing centre', Nat Cell Biol, 18: 65-75.

Farina, F., N. Ramkumar, L. Brown, D. Samandar Eweis, J. Anstatt, T. Waring, J. Bithell, G. Scita, M. Thery, L. Blanchoin, T. Zech, and B. Baum. 2019. 'Local actin nucleation tunes centrosomal microtubule nucleation during passage through mitosis', EMBO J, 38.

Fava, L. L., F. Schuler, V. Sladky, M. D. Haschka, C. Soratroi, L. Eiterer, E. Demetz, G. Weiss, S. Geley, E. A. Nigg, and A. Villunger. 2017. 'The PIDDosome activates p53 in response to supernumerary centrosomes', Genes Dev, 31: 34-45.

Feather, S. A., A. S. Woolf, D. Donnai, S. Malcolm, and R. M. Winter. 1997. 'The oral-facial-digital syndrome type 1 (OFD1), a cause of polycystic kidney disease and associated malformations, maps to Xp22.2-Xp22.3', Hum Mol Genet, 6: 1163-7.

Ferrante, M. I., G. Giorgio, S. A. Feather, A. Bulfone, V. Wright, M. Ghiani, A. Selicorni, L. Gammaro, F. Scolari, A. S. Woolf, O. Sylvie, L. Bernard, S. Malcolm, R. Winter, A. Ballabio, and B. Franco. 2001. 'Identification of the gene for oral-facial-digital type I syndrome', Am J Hum Genet, 68: 569-76.

Ferrante, M. I., A. Zullo, A. Barra, S. Bimonte, N. Messaddeq, M. Studer, P. Dolle, and B. Franco. 2006. 'Oralfacial-digital type I protein is required for primary cilia formation and left-right axis specification', Nat Genet, 38: 112-7.

Field, M., I. E. Scheffer, D. Gill, M. Wilson, L. Christie, M. Shaw, A. Gardner, G. Glubb, L. Hobson, M. Corbett, K. Friend, S. Willis-Owen, and J. Gecz. 2012. 'Expanding the molecular basis and phenotypic spectrum of X-linked Joubert syndrome associated with OFD1 mutations', Eur J Hum Genet, 20: 806-9.

Fong, C. S., G. Mazo, T. Das, J. Goodman, M. Kim, B. P. O'Rourke, D. Izquierdo, and M. F. Tsou. 2016. '53BP1 and USP28 mediate p53-dependent cell cycle arrest in response to centrosome loss and prolonged mitosis', Elife, 5 .

Ganem, N. J., H. Cornils, S. Y. Chiu, K. P. O'Rourke, J. Arnaud, D. Yimlamai, M. Thery, F. D. Camargo, and D. Pellman. 2014. 'Cytokinesis failure triggers hippo tumor suppressor pathway activation', Cell, 158: 833-48. 
Giorgio, G., M. Alfieri, C. Prattichizzo, A. Zullo, S. Cairo, and B. Franco. 2007. 'Functional characterization of the OFD1 protein reveals a nuclear localization and physical interaction with subunits of a chromatin remodeling complex', Mol Biol Cell, 18: 4397-404.

He, F., H. P. Wollscheid, U. Nowicka, M. Biancospino, E. Valentini, A. Ehlinger, F. Acconcia, E. Magistrati, S. Polo, and K. J. Walters. 2016. 'Myosin VI Contains a Compact Structural Motif that Binds to Ubiquitin Chains', Cell Rep, 14: 2683-94.

Inoue, D., D. Obino, J. Pineau, F. Farina, J. Gaillard, C. Guerin, L. Blanchoin, A. M. Lennon-Dumenil, and M. Thery. 2019. 'Actin filaments regulate microtubule growth at the centrosome', EMBO J, 38.

Kall, L., J. D. Canterbury, J. Weston, W. S. Noble, and M. J. MacCoss. 2007. 'Semi-supervised learning for peptide identification from shotgun proteomics datasets', Nat Methods, 4: 923-5.

Keller, A., A. I. Nesvizhskii, E. Kolker, and R. Aebersold. 2002. 'Empirical statistical model to estimate the accuracy of peptide identifications made by MS/MS and database search', Anal Chem, 74: 5383-92.

Kruppa, A. J., and F. Buss. 2018. 'Actin cages isolate damaged mitochondria during mitophagy', Autophagy: 1-2.

Lambrus, B. G., V. Daggubati, Y. Uetake, P. M. Scott, K. M. Clutario, G. Sluder, and A. J. Holland. 2016. 'A USP28-53BP1-p53-p21 signaling axis arrests growth after centrosome loss or prolonged mitosis', The Journal of cell biology, 214: 143-53.

Lopes, C. A., S. L. Prosser, L. Romio, R. A. Hirst, C. O'Callaghan, A. S. Woolf, and A. M. Fry. 2011. 'Centriolar satellites are assembly points for proteins implicated in human ciliopathies, including oral-facial-digital syndrome 1', J Cell Sci, 124: 600-12.

Magistrati, E., and S. Polo. 2020. 'Myomics: myosin VI structural and functional plasticity', Curr Opin Struct Biol, 67: 33-40.

Malicki, J. J., and C. A. Johnson. 2017. 'The Cilium: Cellular Antenna and Central Processing Unit', Trends Cell Biol, 27: 126-40.

Meitinger, F., J. V. Anzola, M. Kaulich, A. Richardson, J. D. Stender, C. Benner, C. K. Glass, S. F. Dowdy, A. Desai, A. K. Shiau, and K. Oegema. 2016. '53BP1 and USP28 mediate p53 activation and G1 arrest after centrosome loss or extended mitotic duration', The Journal of cell biology, 214: 155-66.

Mikule, K., B. Delaval, P. Kaldis, A. Jurcyzk, P. Hergert, and S. Doxsey. 2007. 'Loss of centrosome integrity induces p38-p53-p21-dependent G1-S arrest', Nat Cell Biol, 9: 160-70.

Mironov, A. A., and G. V. Beznoussenko. 2013. 'Correlative microscopy', Methods Cell Biol, 113: 209-55.

Morleo, M., S. Brillante, U. Formisano, L. Ferrante, F. Carbone, D. Iaconis, A. Palma, V. Buonomo, A. S. Maione, P. Grumati, C. Settembre, and B. Franco. 2020. 'Regulation of autophagosome biogenesis by OFD1-mediated selective autophagy', EMBO J: e105120.

Morleo, M., and B. Franco. 2019. 'The Autophagy-Cilia Axis: An Intricate Relationship', Cells, 8.

Morleo, M., and B. Franco. 2020. 'OFD Type I syndrome: lessons learned from a rare ciliopathy', Biochem Soc Trans, 48: 1929-39.

Mukherjea, M., M. Y. Ali, C. Kikuti, D. Safer, Z. Yang, H. Sirkia, V. Ropars, A. Houdusse, D. M. Warshaw, and H. L. Sweeney. 2014. 'Myosin VI must dimerize and deploy its unusual lever arm in order to perform its cellular roles', Cell Rep, 8: 1522-32.

Nesvizhskii, A. I., A. Keller, E. Kolker, and R. Aebersold. 2003. 'A statistical model for identifying proteins by tandem mass spectrometry', Anal Chem, 75: 4646-58.

O'Loughlin, T., T. A. Masters, and F. Buss. 2018. 'The MYO6 interactome reveals adaptor complexes coordinating early endosome and cytoskeletal dynamics', EMBO Rep, 19.

Pampliega, O., and A. M. Cuervo. 2016. 'Autophagy and primary cilia: dual interplay', Curr Opin Cell Biol, 39: 1-7.

Park, S. M., J. S. Lim, S. Ramakrishina, S. H. Kim, W. K. Kim, J. Lee, H. C. Kang, J. F. Reiter, D. S. Kim, H. H. Kim, and J. H. Lee. 2018. 'Brain Somatic Mutations in MTOR Disrupt Neuronal Ciliogenesis, Leading to Focal Cortical Dyslamination', Neuron, 99: 83-97 e7.

Penengo, L., M. Mapelli, A. G. Murachelli, S. Confalonieri, L. Magri, A. Musacchio, P. P. Di Fiore, S. Polo, and T. R. Schneider. 2006. 'Crystal structure of the ubiquitin binding domains of rabex-5 reveals two modes of interaction with ubiquitin', Cell, 124: 1183-95.

Rappsilber, J., Y. Ishihama, and M. Mann. 2003. 'Stop and go extraction tips for matrix-assisted laser desorption/ionization, nanoelectrospray, and LC/MS sample pretreatment in proteomics', Anal Chem, 75: 663-70.

Reiter, J. F., and M. R. Leroux. 2017. 'Genes and molecular pathways underpinning ciliopathies', Nat Rev Mol Cell Biol, 18: 533-47.

Romio, L., A. M. Fry, P. J. Winyard, S. Malcolm, A. S. Woolf, and S. A. Feather. 2004. 'OFD1 is a centrosomal/basal body protein expressed during mesenchymal-epithelial transition in human nephrogenesis', $J$ Am Soc Nephrol, 15: 2556-68. 
Sahlender, D. A., R. C. Roberts, S. D. Arden, G. Spudich, M. J. Taylor, J. P. Luzio, J. Kendrick-Jones, and F. Buss. 2005. 'Optineurin links myosin VI to the Golgi complex and is involved in Golgi organization and exocytosis', The Journal of cell biology, 169: 285-95.

Sanchez, I., and B. D. Dynlacht. 2016. 'Cilium assembly and disassembly', Nat Cell Biol, 18: 711-7.

Shevchenko, A., M. Wilm, O. Vorm, and M. Mann. 1996. 'Mass spectrometric sequencing of proteins silver-stained polyacrylamide gels', Anal Chem, 68: 850-8.

Singla, V., M. Romaguera-Ros, J. M. Garcia-Verdugo, and J. F. Reiter. 2010. 'Ofd1, a human disease gene, regulates the length and distal structure of centrioles', Dev Cell, 18: 410-24.

Spudich, G., M. V. Chibalina, J. S. Au, S. D. Arden, F. Buss, and J. Kendrick-Jones. 2007. 'Myosin VI targeting to clathrin-coated structures and dimerization is mediated by binding to Disabled-2 and PtdIns(4,5)P2', Nature cell biology, 9: 176-83.

Tang, Z., M. G. Lin, T. R. Stowe, S. Chen, M. Zhu, T. Stearns, B. Franco, and Q. Zhong. 2013. 'Autophagy promotes primary ciliogenesis by removing OFD1 from centriolar satellites', Nature, 502: 254-7.

Thauvin-Robinet, C., J. S. Lee, E. Lopez, V. Herranz-Perez, T. Shida, B. Franco, L. Jego, F. Ye, L. Pasquier, P. Loget, N. Gigot, B. Aral, C. A. Lopes, J. St-Onge, A. L. Bruel, J. Thevenon, S. Gonzalez-Granero, C. Alby, A. Munnich, M. Vekemans, F. Huet, A. M. Fry, S. Saunier, J. B. Riviere, T. Attie-Bitach, J. M. Garcia-Verdugo, L. Faivre, A. Megarbane, and M. V. Nachury. 2014. 'The oral-facial-digital syndrome gene C2CD3 encodes a positive regulator of centriole elongation', Nat Genet, 46: 905-11.

Tumbarello, D. A., B. J. Waxse, S. D. Arden, N. A. Bright, J. Kendrick-Jones, and F. Buss. 2012. 'Autophagy receptors link myosin VI to autophagosomes to mediate Tom1-dependent autophagosome maturation and fusion with the lysosome', Nature cell biology, 14: 1024-35.

Vassilev, L. T., B. T. Vu, B. Graves, D. Carvajal, F. Podlaski, Z. Filipovic, N. Kong, U. Kammlott, C. Lukacs, C. Klein, N. Fotouhi, and E. A. Liu. 2004. 'In vivo activation of the p53 pathway by small-molecule antagonists of MDM2', Science, 303: 844-8.

Wang, L., M. Failler, W. Fu, and B. D. Dynlacht. 2018. 'A distal centriolar protein network controls organelle maturation and asymmetry', Nat Commun, 9: 3938.

Wollscheid, H. P., M. Biancospino, F. He, E. Magistrati, E. Molteni, M. Lupia, P. Soffientini, K. Rottner, U. Cavallaro, U. Pozzoli, M. Mapelli, K. J. Walters, and S. Polo. 2016. 'Diverse functions of myosin VI elucidated by an isoform-specific alpha-helix domain', Nat Struct Mol Biol, 23: 300-08.

Wong, Y. L., J. V. Anzola, R. L. Davis, M. Yoon, A. Motamedi, A. Kroll, C. P. Seo, J. E. Hsia, S. K. Kim, J. W. Mitchell, B. J. Mitchell, A. Desai, T. C. Gahman, A. K. Shiau, and K. Oegema. 2015. 'Reversible centriole depletion with an inhibitor of Polo-like kinase 4', Science, 348: 1155-60.

Zhang, C., C. Li, G. K. Y. Siu, X. Luo, and S. Yu. 2020. 'Distinct Roles of TRAPPC8 and TRAPPC12 in Ciliogenesis via Their Interactions With OFD1', Front Cell Dev Biol, 8: 148.

Zullo, A., D. Iaconis, A. Barra, A. Cantone, N. Messaddeq, G. Capasso, P. Dolle, P. Igarashi, and B. Franco. 2010. 'Kidney-specific inactivation of Ofd1 leads to renal cystic disease associated with upregulation of the mTOR pathway', Hum Mol Genet, 19: 2792-803. 
A

\begin{tabular}{ll}
\hline Gene name & Protein name \\
\hline CGN & Cingulin \\
DSP & Desmoplakin \\
DTX31 & E3 ubiquitin-protein ligase DTX3L \\
EIF3A & Eukaryotic translation initiation factor 3 \\
& subunitA \\
ENAH & Protein enabled homolog \\
GIGYF2 & GRB10-interacting GYF protein 2 \\
NUDC & Nuclear migration protein nudC \\
NUMA1 & Nuclear mitotic apparatus protein 1 \\
OFD1 & Oral-facial-digital syndrome 1 protein \\
PARP9 & Protein mono-ADP-ribosyltransferase \\
RAB11FIP1 & Rab11 family-interacting protein 1 \\
SFPQ & Splicing factor, proline- and glutamine-rich \\
SLC12A4 & Solute carrier family 12 member 4 \\
\hline
\end{tabular}

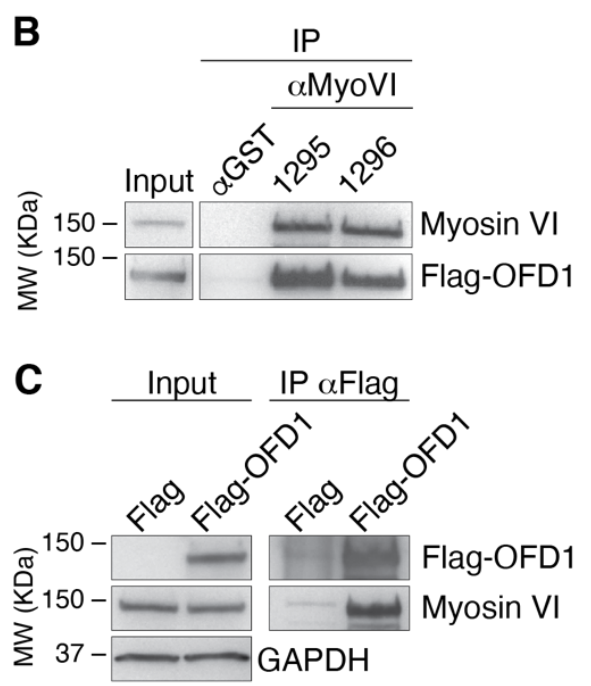

E
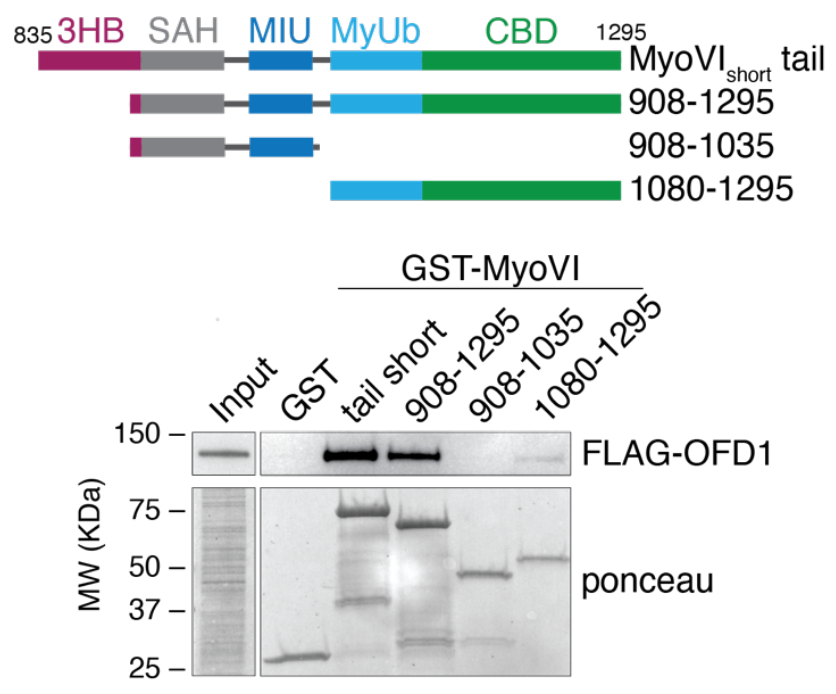

F

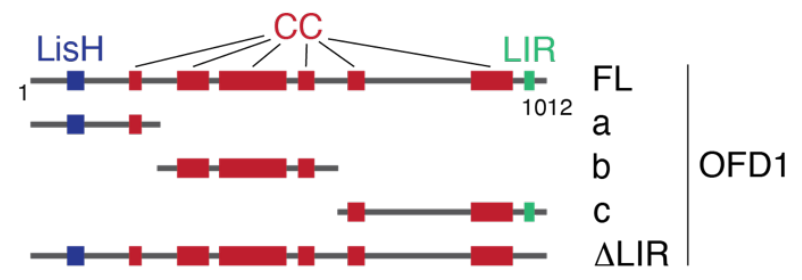

D
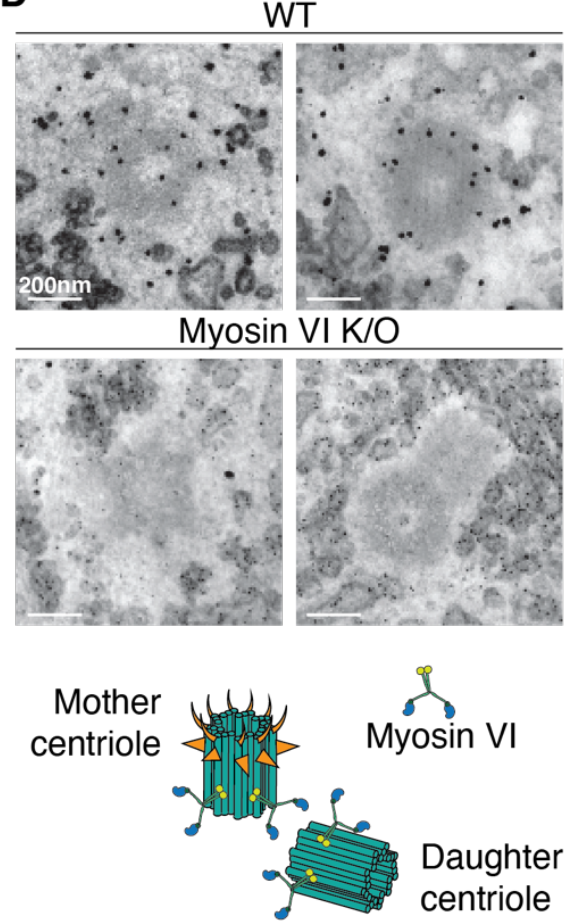

GST

GST-MyoVI Tail

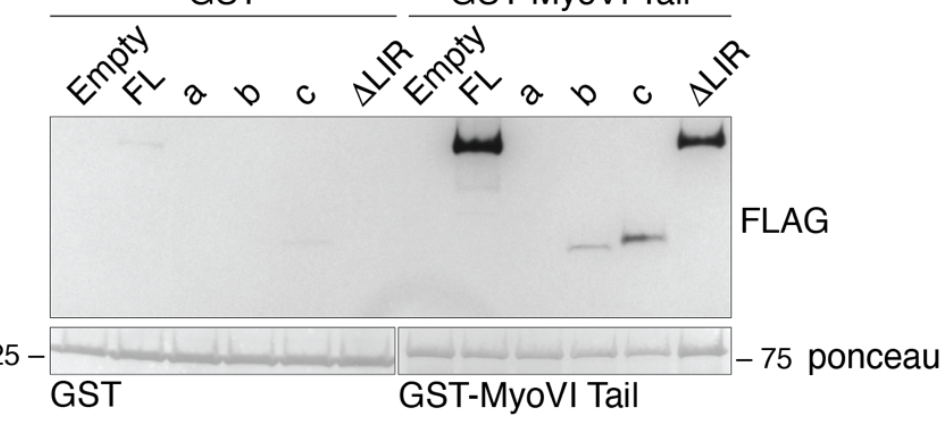




\section{Figure 1: OFD1 interacts with both myosin VI isoforms.}

(A) List of myosin VI interactors found in the four cell lines tested. See Supplementary Table 1 for the full list of interactors.

(B) Total lysates from HEK293T transfected with Flag-OFD1 were IP with anti-myosin VI antibodies (1295 and 1296) and an unrelated rabbit antibody (anti-GST, as control). IB was performed with anti-Flag and anti-myosin VI antibodies.

(C) Total lysates from HEK293T transfected with Flag-OFD1 or Flag (as control) were IP with anti-Flag antibody-conjugated beads. IB was performed with anti-Flag and anti-myosin VI antibodies.

(D) Selected sections deriving from TEM analysis of A549 wild-type versus myosin VI KO cells. The cells were immunogold-labelled with anti-myosin VI antibody. Scale bar, $200 \mathrm{~nm}$. Bottom, representation of the estimated localisation of myosin VI at the centrioles.

(E) GST pulldown assay using the indicated myosin VI constructs or GST alone (as control) and lysates from HEK293T cells transfected with Flag-OFD1 construct. IB was performed with antiFlag antibody. Ponceau staining as indicated.

(F) GST pulldown assay using myosin VI tail (835-1295) construct (or GST alone as control) and lysates from HEK293T cells transfected with the indicated Flag-OFD1 constructs (or Flag alone, as control). IB was performed with anti-Flag antibody. Ponceau staining as indicated. 
A
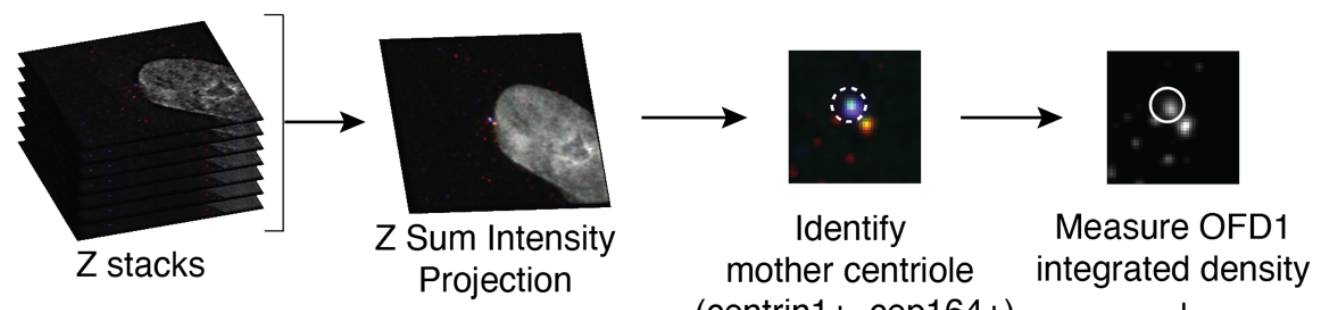
(centrin1+, cep164+)

B
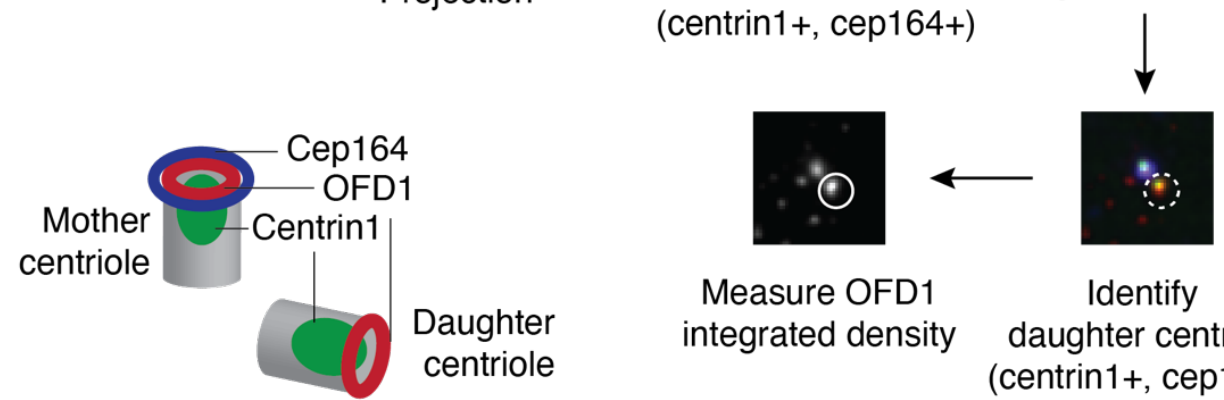

Measure OFD1

Identify integrated density

daughter centriole (centrin1+, cep164-)

OFD1

Centrin1

Cep164

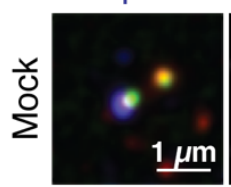

OFD1

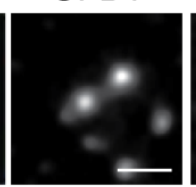

Centrin1

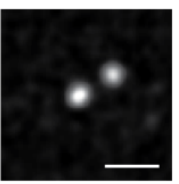

Cep164
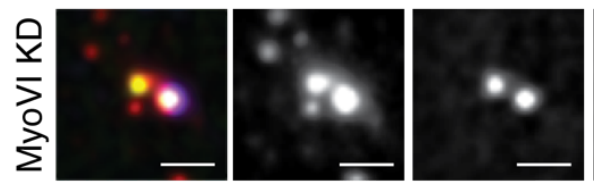

D

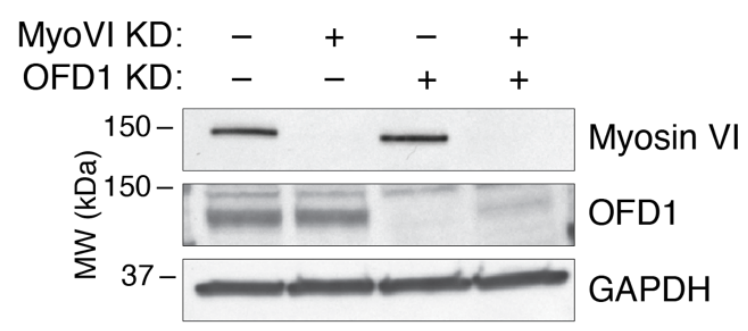

E

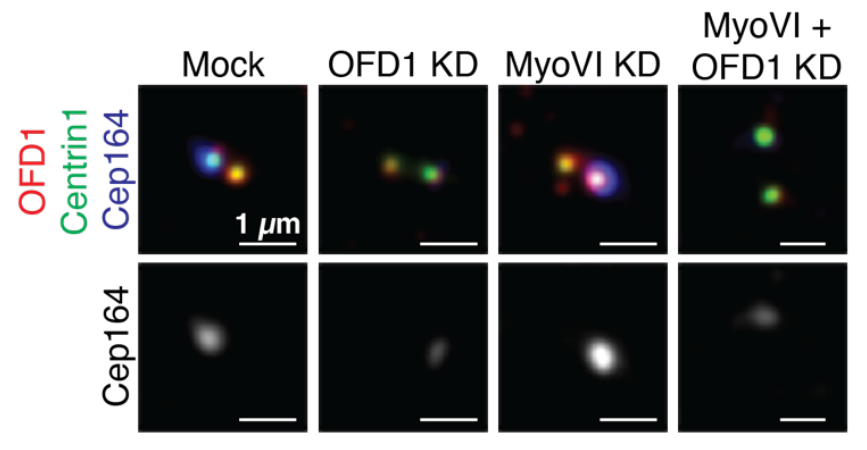

\section{Mother centrioles Daughter centrioles}

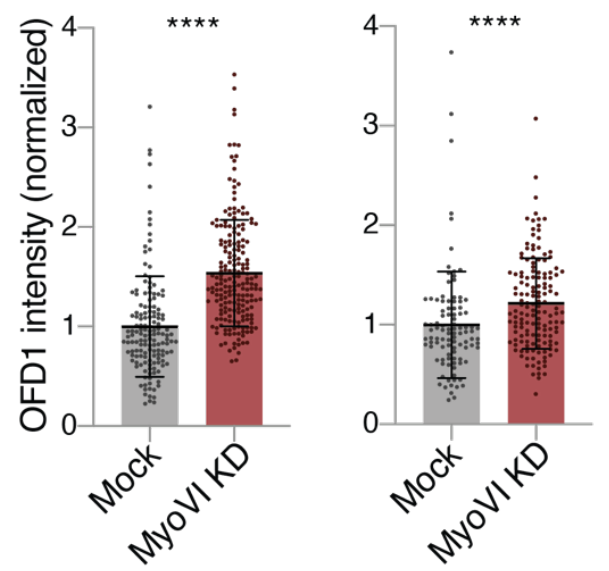

$\mathbf{F}$

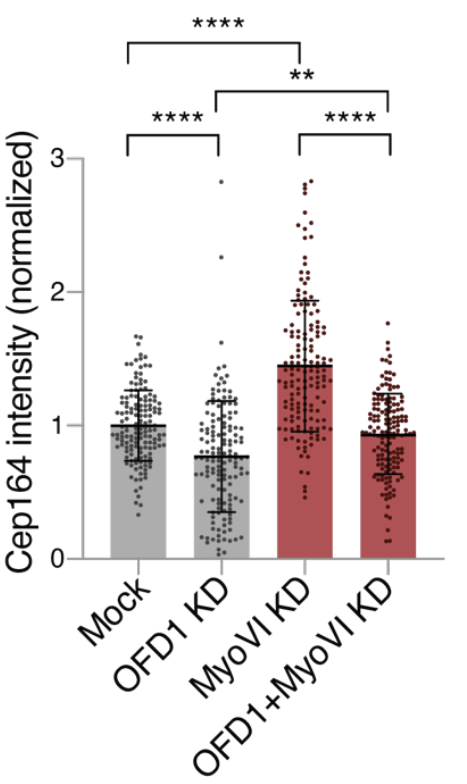




\section{Figure 2: Myosin VI depletion leads to increased OFD1 and Cep164 recruitment at the} centrioles.

(A) A scheme of the IF analysis performed to calculate the total intensity of OFD1 staining at the mother and daughter centrioles.

$(\mathrm{B}, \mathrm{C})$ IF analysis of centriole-associated OFD1 signal. hTERT-RPE1 cells were transfected with siRNA against myosin VI. Four days after transfection, cells were treated with nocodazole (1 hour, $6 \mu \mathrm{g} / \mathrm{ml}$ ) and immunostained with anti-OFD1, anti-centrin1 and anti-cep164 antibodies. Mother centrioles were identified by the coincident staining of centrin1 and cep164, while daughter centrioles were centrin1-only stained. A scheme of the position of the markers used is depicted above. (B) Representative images, scale bar, $1 \mathrm{um}$. (C) Quantification of OFD1 intensity at the mother or daughter centrioles. Results are expressed as fold change with respect to mock average intensity. Bars represent mean \pm SD. Mother centrioles: Mock, $n=148$ cells; MyoVI KD, n=199 cells, from four independent experiments. Daughter centrioles: Mock, $n=101$ cells; MyoVI KD, $\mathrm{n}=148$ cells, from three independent experiments. $* * * * \mathrm{P}<0,0001$ by Mann-Whitney test.

(D) IB analysis of hTERT-RPE cells treated with the indicated siRNAs with anti-myosin VI and anti-OFD1 antibodies. Anti-GAPDH was used as loading control.

(E-F) IF analysis of cep164 signal. hTERT-RPE1 cells were transfected with siRNA against myosin VI and/or OFD1. Four days after transfection, cells were treated with nocodazole (1 hour, $6 \mu \mathrm{g} / \mathrm{ml}$ ) and immunostained with anti-OFD1, anti-centrin1 and anti-cep164 antibodies. (E) Representative images. Scale bar, 1 um. (F) Quantification of cep164 intensity at the mother centrioles. Results are expressed as fold change with respect to mock average intensity. Bars represent mean \pm SD. Mock, $n=147$ cells; OFD1 KD, $n=146$ cells; MyoVI KD, $n=150$ cells; MyoVI

+ OFD1 KD, $\mathrm{n}=151$ cells, from four independent experiments. $* * \mathrm{P}<0,005$; **** $\mathrm{P}<0,0001$ by Kruskal-Wallis test. 
A

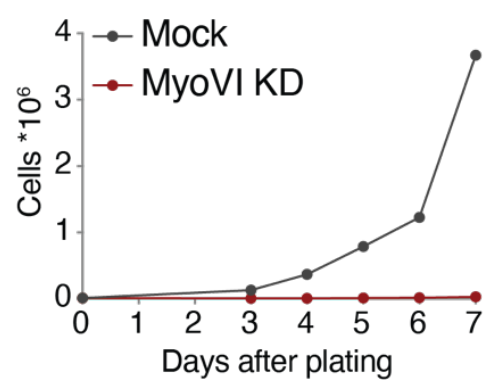

B

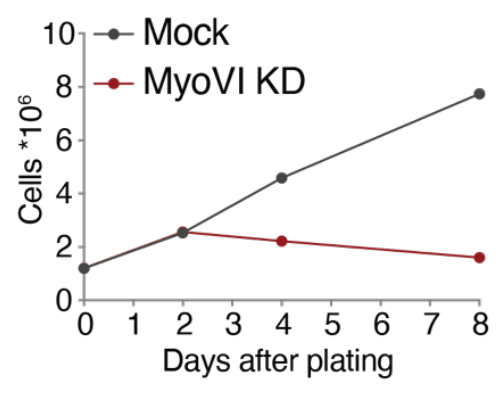

F

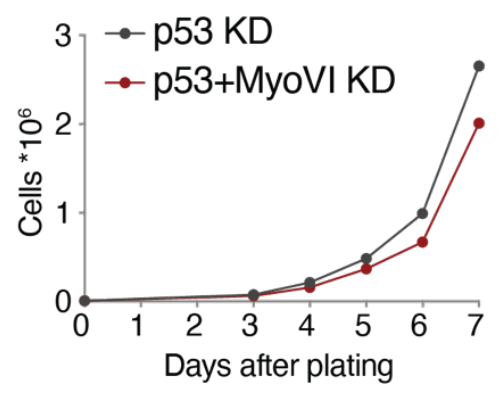

C

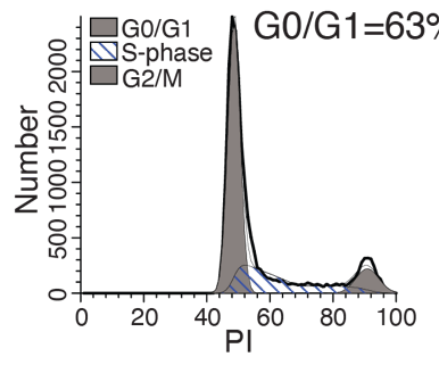

D

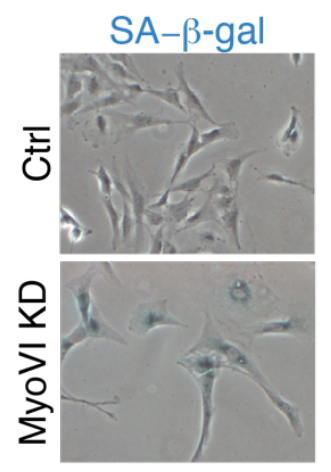

G

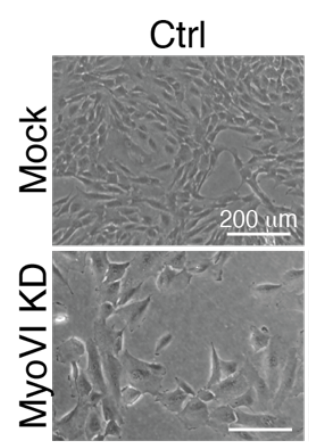

MyoVI KD

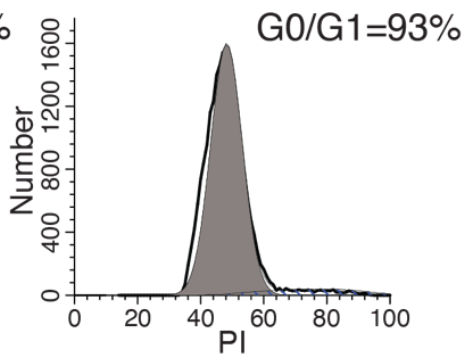

E

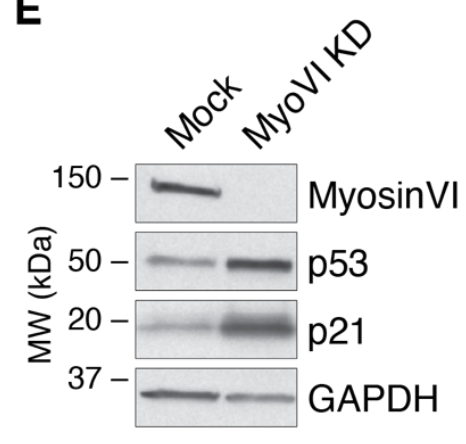

H

I Mother centrioles Daughter centrioles $\mathbf{J}$

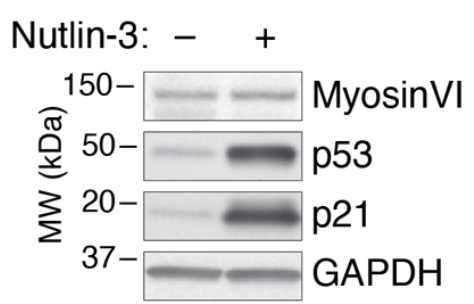

siRNA p53

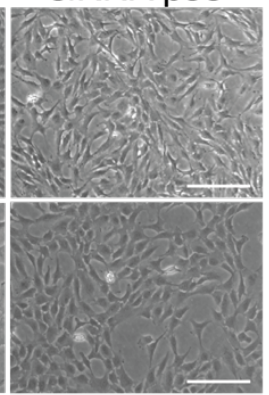

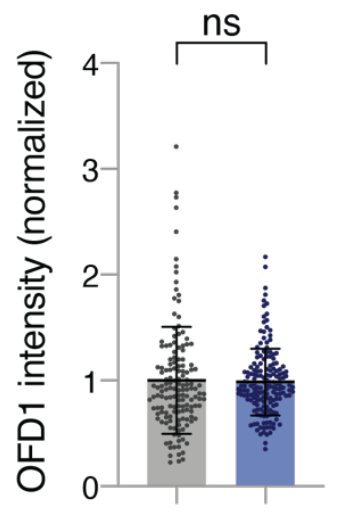

Nutlin-3:

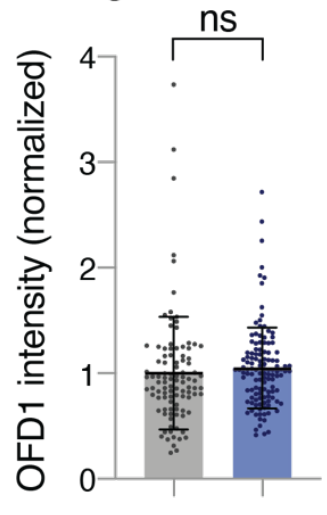

Nutlin-3: - +

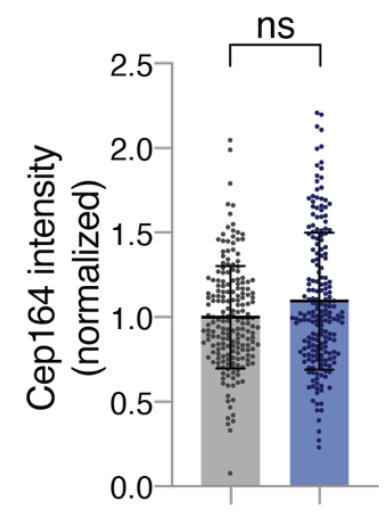

Nutlin-3: 


\section{Figure 3: Myosin VI depletion leads to p53 activation and cell cycle arrest.}

(A) Growth curve of hTERT-RPE1 cells transfected with myosin VI siRNA. A representative plot of three independent experiments is shown.

(B) Growth curve of BJ-hTERT cells transfected with myosin VI siRNA. A representative plot of two independent experiments is shown.

(C) Analysis of DNA content in hTERT-RPE1 cells stably expressing a myosin VI shRNA. After 10 days of doxycycline induction, the cells were stained with Propidium Iodide (PI) and analysed by FACS. Ctrl = control cells, not induced.

(D) Senescence-associated $\beta$-gal assay (SA- $\beta$-gal) of cells treated as in C.

(E) IB analysis of hTERT-RPE1 cells transfected with myosin VI siRNA, with anti-myosin VI, anti-p53 and anti-p21 antibodies. Anti-GAPDH was used as loading control.

(F) Growth curve of hTERT-RPE1 cells transfected with the indicated p53 and myosin VI siRNAs. A representative plot of three independent experiments is shown.

(G) Representative bright field images of cells treated with the indicated p53 and myosin VI siRNAs.

(H) IB analysis with anti-myosin VI and anti-OFD1 antibodies of hTERT-RPE cells treated with Nutlin-3, or not treated as control. Anti-GAPDH was used as loading control.

(I) Quantification of OFD1 intensity at the mother or daughter centrioles. hTERT-RPE1 cells were transfected with siRNA against myosin VI. Four days after transfection, cells were treated with nocodazole (1 hour, $6 \mu \mathrm{g} / \mathrm{ml}$ ) and immunostained with anti-OFD1, anti-centrin 1 and anti-cep164 antibodies. Mother centrioles were identified by the coincident staining of centrin1 and cep164, while daughter centrioles were centrin1-only stained. Results are expressed as fold change with respect to mock average intensity. Bars represent mean \pm SD. Mother centrioles: Mock, $n=148$ cells; MyoVI KD n=169 cells, from four independent experiments. Daughter centrioles: Mock $\mathrm{n}=101$ cells; MyoVI KD; $\mathrm{n}=122$ cells, from three independent experiments. $\mathrm{ns}$, not significant by Mann-Whitney test.

(J) Quantification of cep164 intensity at the mother centrioles in hTERT-RPE1 cells treated as in (I). Results are expressed as fold change with respect to mock average intensity. Bars represent mean \pm SD. Mock, $n=195$ cells; MyoVI KD n=196 cells, from four independent experiments. ns, not significant by Mann-Whitney test. 
A

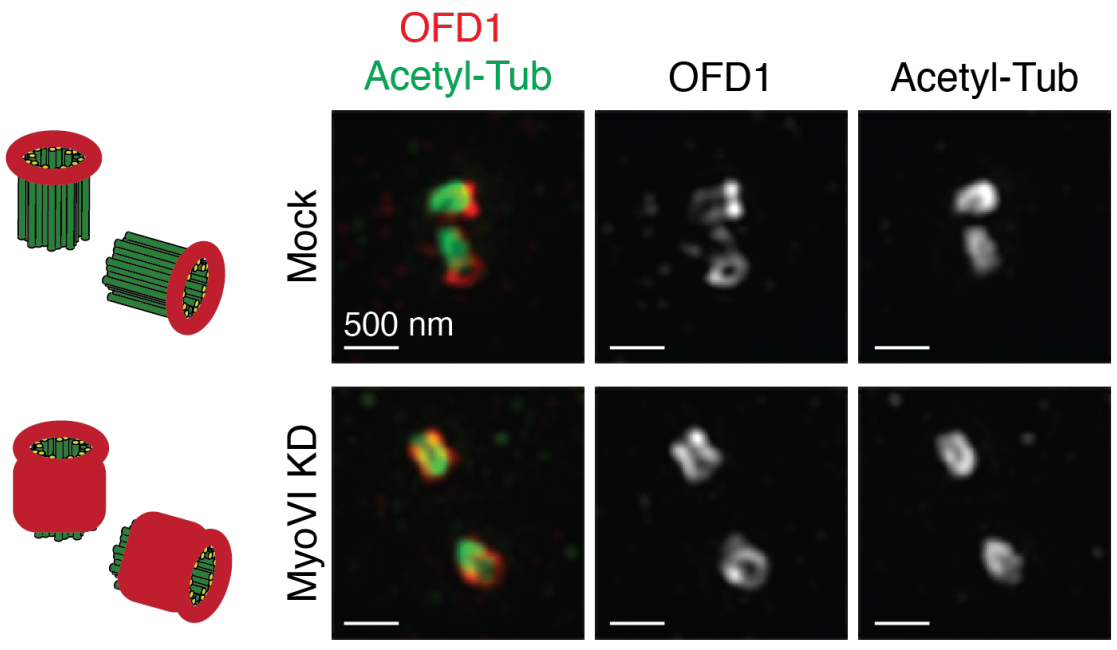

B
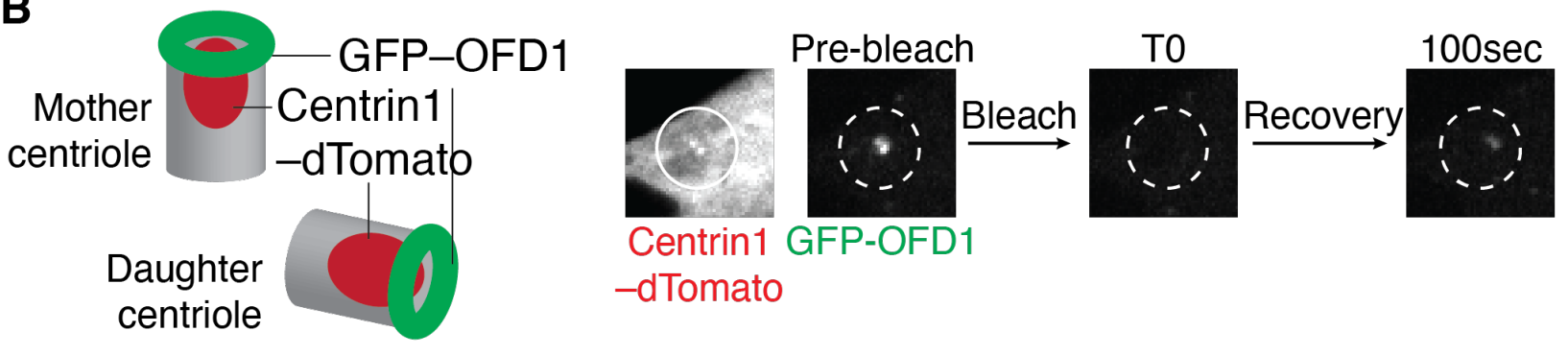

C

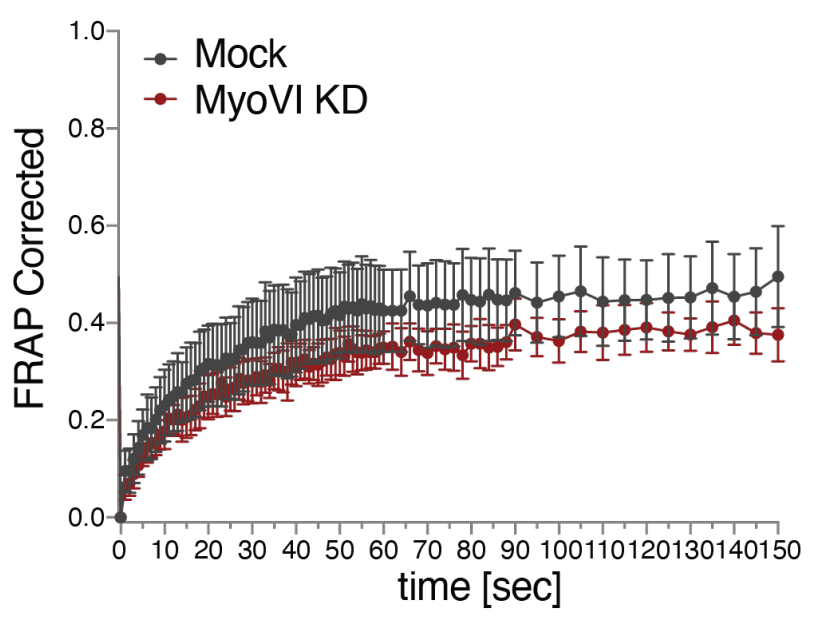

D
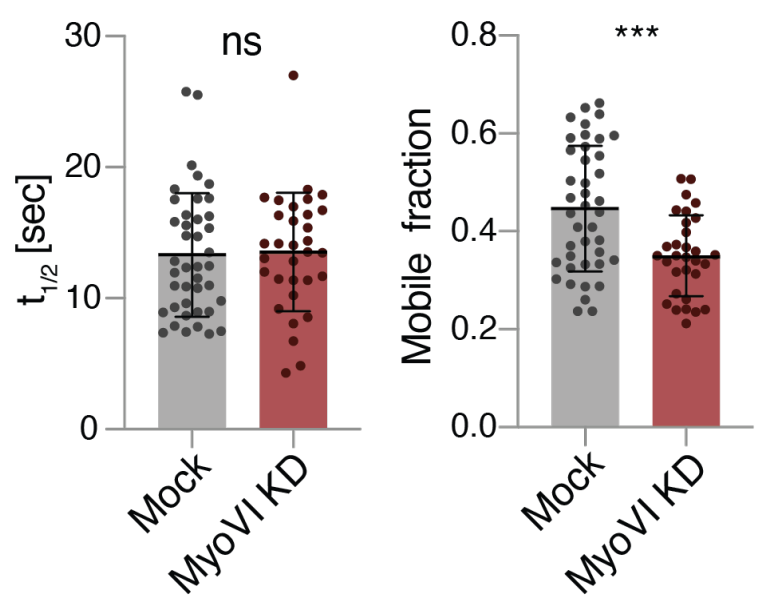
Figure 4: Lack of myosin VI alters the mobility and localisation of OFD1 at the centrioles. (A) Super-resolution analysis of OFD1 localisation at the centrioles. hTERT-RPE1 cells were transfected with siRNA against myosin VI, immunostained with anti-OFD1 and anti-acetylated tubulin antibodies and visualised using structured illumination microscopy (SIM). Representative images, scale bar, $500 \mathrm{~nm}$. A scheme of the estimated localisation of OFD1 in the two conditions is depicted on the right side.

(B-D) FRAP analysis of centriole-associated GFP-OFD1. hTERT-RPE cells stably expressing GFP-OFD1 and centrin1-dTomato were transfected with siRNA against myosin VI. After four days, cells were treated with nocodazole (1 hour, $6 \mu \mathrm{g} / \mathrm{ml}$ ) and subjected to live-cell imaging. (B) Left: a scheme of the localisation of GFP-OFD1 and the centriole marker centrin1-dTomato. Right: a scheme of photobleaching and recovery of GFP-OFD1 at the centrioles.

(C) A representative graph of one out of three experiments. For each time point, the fraction of recovery of GFP-OFD1 is shown. Results are expressed as means with 95\% confidence interval. $\mathrm{n}=12$ cells (Mock), $\mathrm{n}=13$ cells (MyoVI KD).

(D) Quantification of the half-time of fluorescence recovery $\left(\mathrm{t}_{1 / 2}\right.$, ) and of the mobile fraction of GFP-OFD1. Results are expressed as mean \pm SD. $n=41$ cells (Mock), $n=31$ cells (MyoVI KD), from three independent experiments. ns, not significant; *** $\mathrm{P}<0,0005$ by Unpaired T-test. 
A

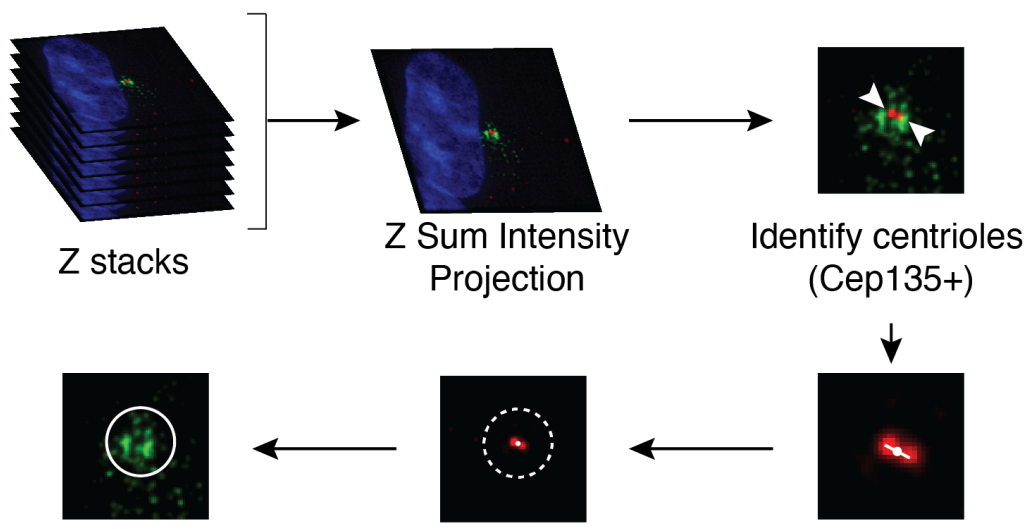

Measure PCM1

Use middle point as

Find middle point

integrated density center of a 3um circle between the centrioles

B
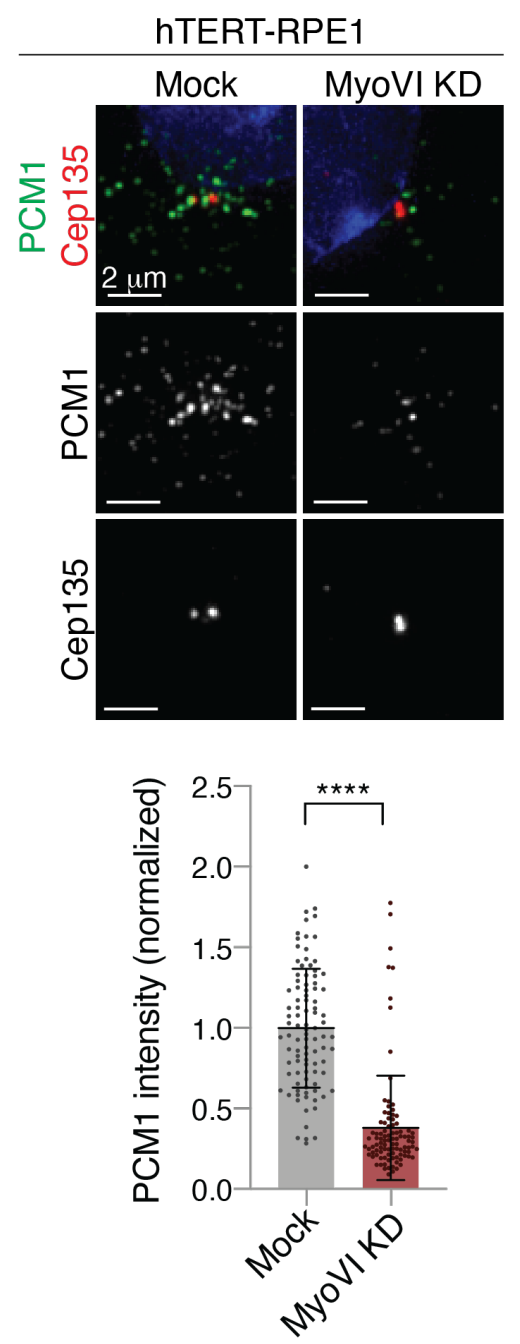

C
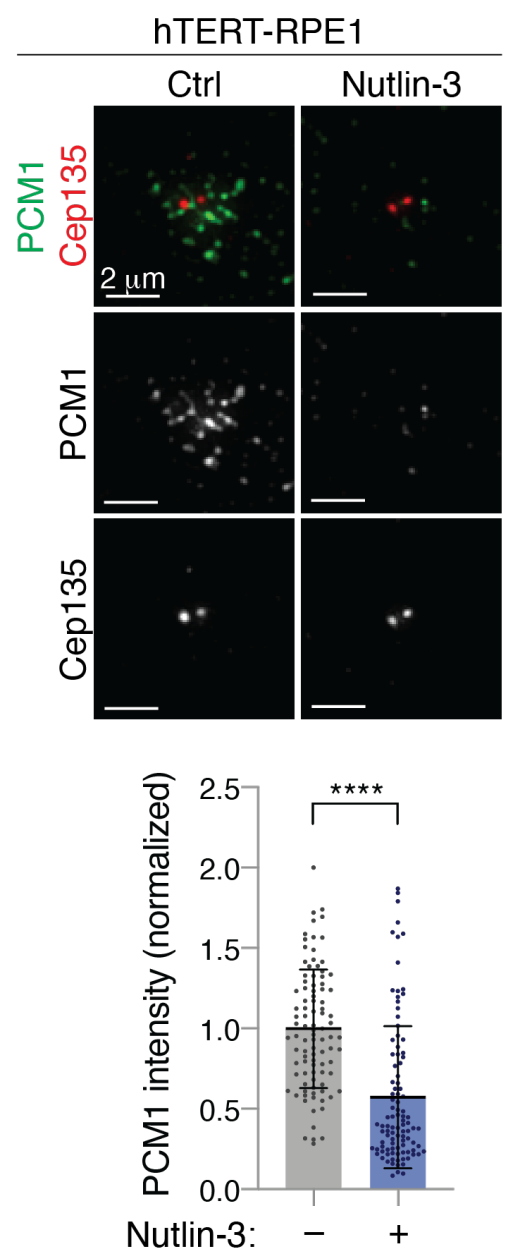

D
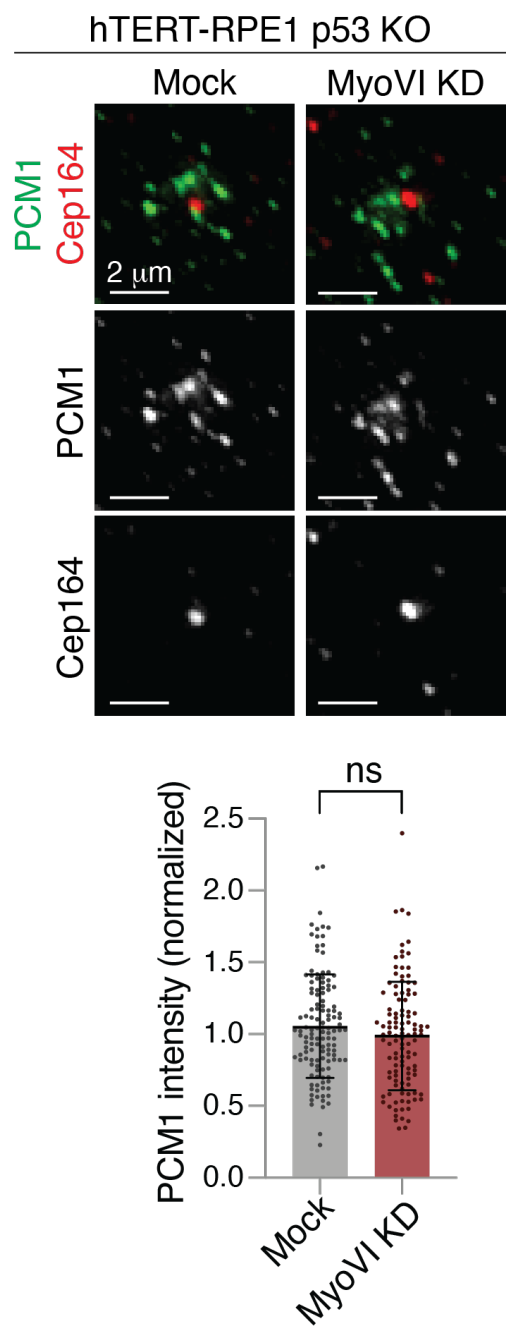
Figure 5: Myosin VI depletion affects the centriolar satellites via p53.

(A) A scheme of the IF analysis performed to calculate the total intensity of satellite staining that surrounds the centrioles. The centriole marker cep135 or cep164 are used to define the centre of a $3 \mu \mathrm{m}$ circle, in which the intensity of the satellite marker PCM1 was calculated.

(B) IF analysis of PCM1 signal. hTERT-RPE1 cells were transfected with siRNA against myosin VI and immunostained with anti-PCM1 and anti-cep135 antibodies. Upper panel, representative images, scale bar, $2 \mu \mathrm{m}$. Lower panel, quantification of PCM1 intensity. Results are expressed as fold change with respect to mock average intensity. Bars represent mean $\pm S D$. Mock, $n=96$ cell; MyoVI KD, $\mathrm{n}=98$ cells, from two independent experiments. **** $\mathrm{P}<0,0001$ by Mann-Whitney test. (C) IF analysis of PCM1 signal. hTERT-RPE1 cells were treated with Nutlin-3 for 24 hours and immunostained with anti-PCM1 and anti-cep135 antibodies. Panels as in B. Mock, n=96 cells; Nutlin-3, $\mathrm{n}=100$ cells, from two independent experiments. $* * * * \mathrm{P}<0,0001$ by Mann-Whitney test. (D) IF analysis of PCM1 signal. hTERT-RPE1 p53 KO cells were transfected with siRNA against myosin VI and immunostained with anti-PCM1 and anti-cep164 antibodies. Panels as in B. Quantification of PCM1 intensity refers to a $3 \mu \mathrm{m}$ circle around the mother centriole, identified with anti-cep164 staining. Mock, $n=128$ cells; MyoVI KD, $n=114$ cells from three independent experiments. ns, not significant by Mann-Whitney test. 
A

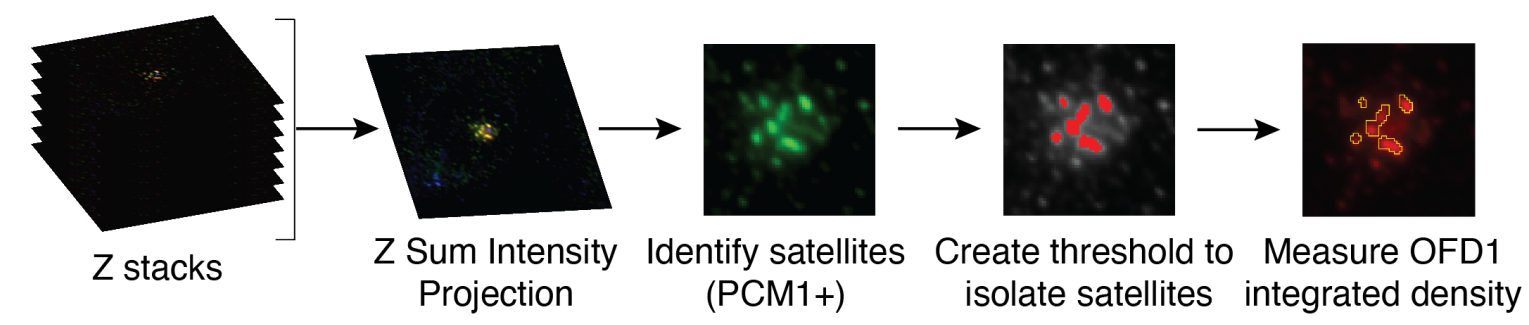

B
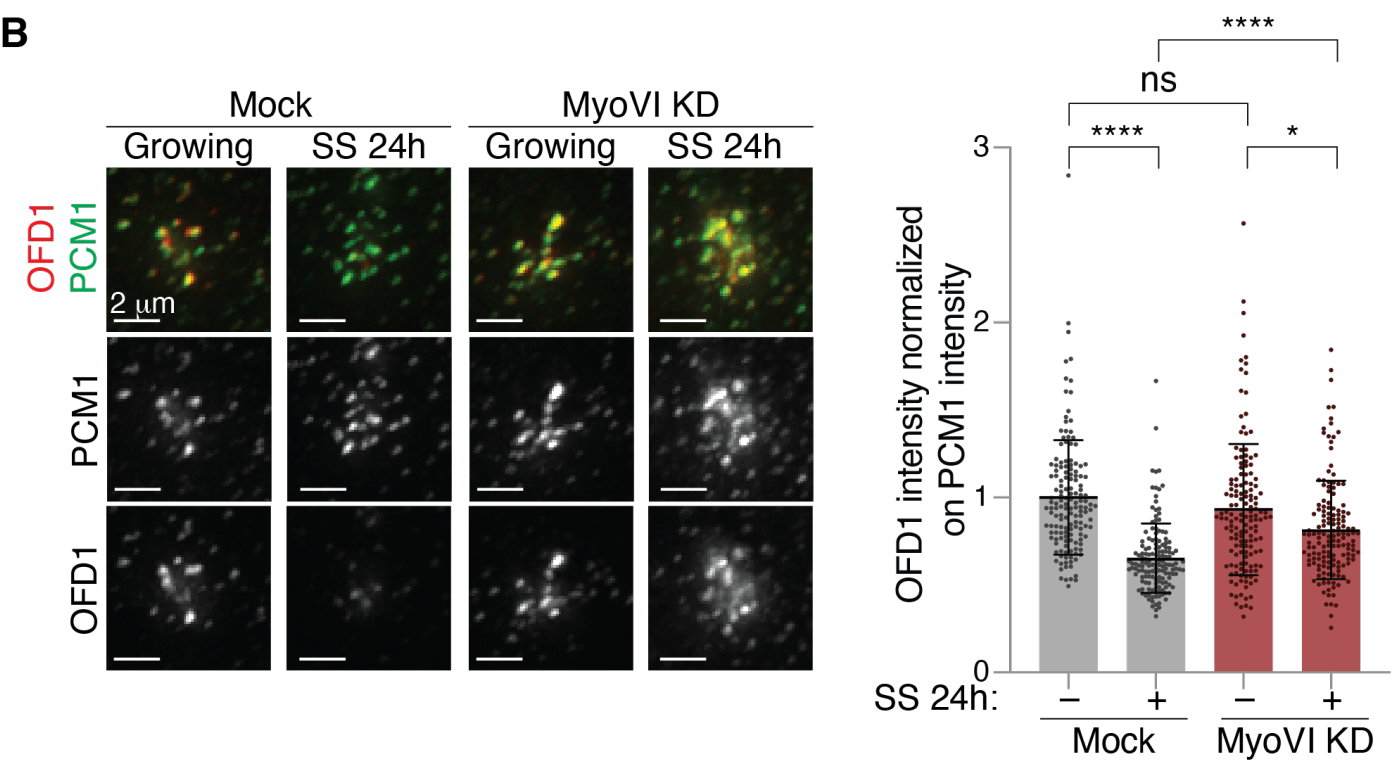

C
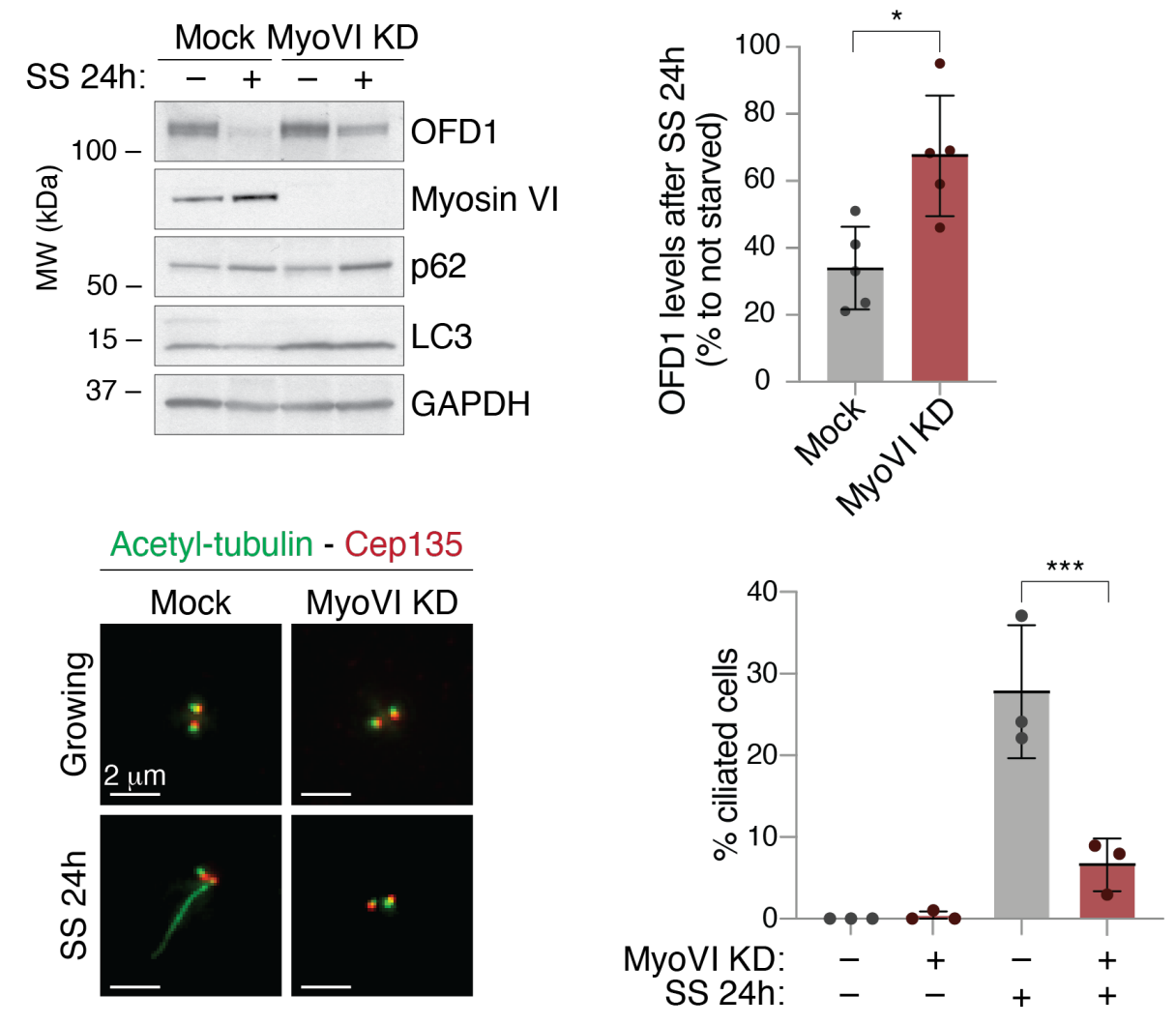


\section{Figure 6: Myosin VI contributes to OFD1 removal from the centriolar satellites required for} ciliogenesis.

(A) A scheme of the IF analysis performed to calculate the total intensity of OFD1 staining at the centriolar satellites.

(B) IF analysis of OFD1 signal at the centriolar satellites upon serum starvation. hTERT-RPE1 p53 KO cells were transfected with siRNA against myosin VI. After four days, cells were fixed (growing) or serum starved for 24 hours (SS). Cells were immunostained with anti-OFD1 and antiPCM1 antibodies. The intensity of OFD1 signal in the area covered by PCM1 was quantified and normalised against the intensity of PCM1 staining in the same area. Left, representative images, scale bar, $2 \mu \mathrm{m}$. Right, results are expressed as fold change with respect to mock average intensity. Bars represent mean \pm SD. Mock_growing, $n=150$ cells; Mock_SS, n=149 cells; MyoVI KD_growing, $n=149$ cells; MyoVI KD_SS, $n=150$ cells, from three independent experiments. ns, not significant; $* \mathrm{P}<0,05 ; * * * * \mathrm{P}<0,0001$ by Kruskal-Wallis test.

(C) IB analysis of OFD1 after serum starvation in control and myosin VI-depleted cells. hTERTRPE1 p53 KO cells were transfected with siRNA against myosin VI. After four days, cells were serum starved for 24 hours (SS). Lysates were analysed by IB with anti-OFD1, anti-myosin VI, anti-p62, and anti-LC3 antibodies. Anti-GAPDH was used as loading control. The amount of OFD1 protein was normalised against GAPDH signal and is expressed as percentage of OFD levels in cells grown in serum-starved conditions compared to cells grown in media containing serum. Bars represent mean \pm SD. $\mathrm{n}=5$ independent experiments. ${ }^{*} \mathrm{P}<0,05$ by Kruskal-Wallis test. (D) IF analysis of primary cilium upon serum starvation. hTERT-RPE1 p53 KO cells were transfected with siRNA against myosin VI. After four days, cells were fixed (growing) or serum starved for 24 hours (SS). Cells were immunostained with anti-acetylated tubulin (to identify the cilia), anti-cep135 (to identify the centrioles) and DAPI. Left, representative images, scale bar, 2 $\mu \mathrm{m}$. Right, results are expressed as fold change with respect to mock average intensity. Bars represent mean \pm SD. $n=3$ independent experiments. 100-200 cells/condition were counted for each experiment. 

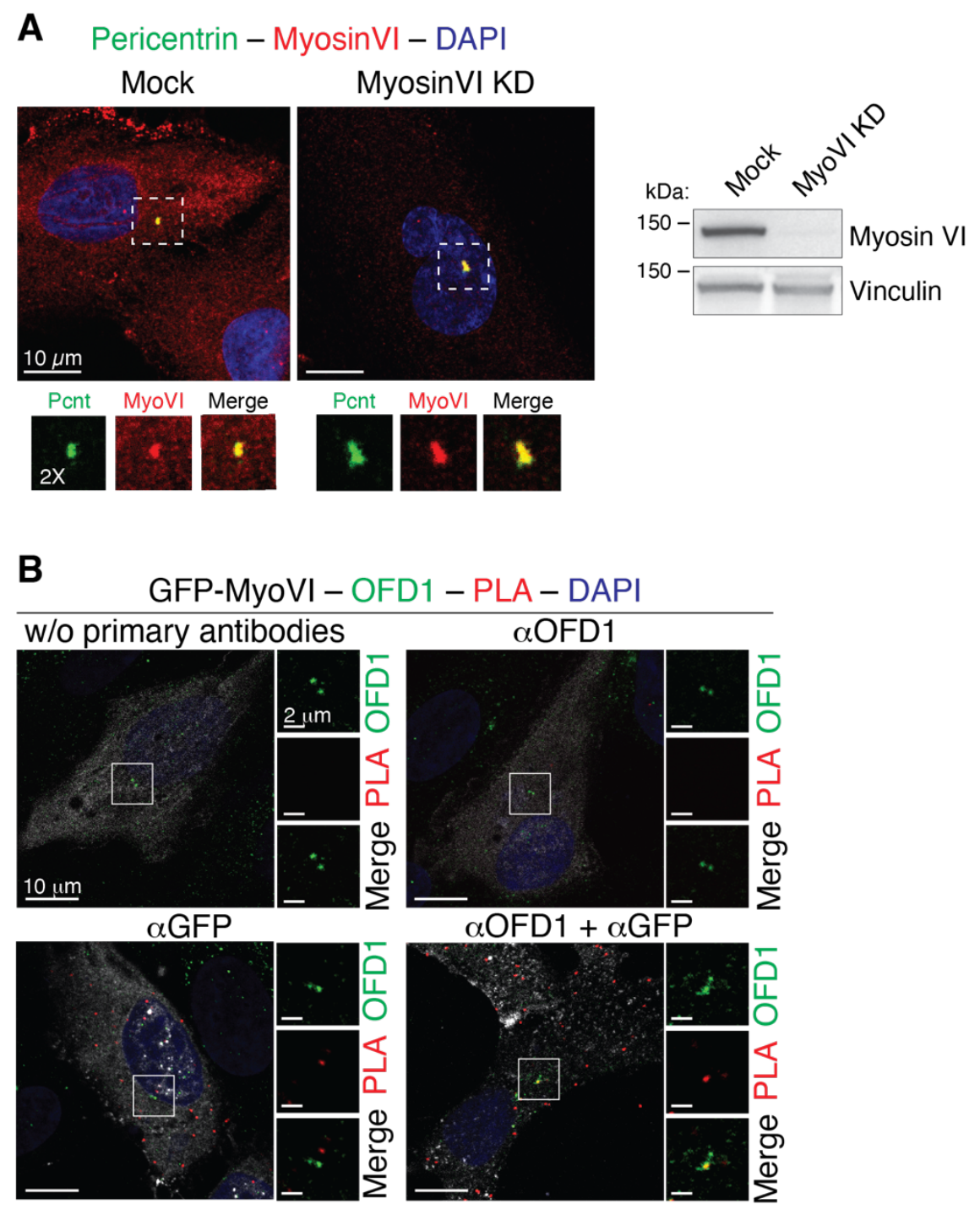

\section{Supplementary Figure 1: Myosin VI localisation at the centrosome.}

(A) hTERT-RPE1 cells were transfected with siRNA against myosin VI and immunostained with anti-myosin VI and anti-pericentrin antibodies. Co-localisation between myosin VI and pericentrin, maintained also in myosin VI KD cells, does not allow us to draw definitive conclusions about myosin VI centrosome localisation. Representative images are shown, scale bar, $10 \mu \mathrm{m}$.

(B) Proximity ligation assay (PLA) in hTERT-RPE1 cells overexpressing GFP-myosin $\mathrm{VI}_{\text {short }}$ fulllength, using anti-OFD1 and anti-GFP antibodies. After PLA assay, counterstaining with fluorescently-labelled secondary antibodies allowed the detection of OFD1 and GFP localisation. Representative images of technical controls with single or no primary antibodies are shown. Scale bar, $10 \mu \mathrm{m}$ ( $2 \mu \mathrm{m}$ for the magnification). 
bioRxiv preprint doi: https://doi.org/10.1101/2021.06.18.448975; this version posted June 19, 2021. The copyright holder for this preprint (which was not certified by peer review) is the author/funder. All rights reserved. No reuse allowed without permission.

A

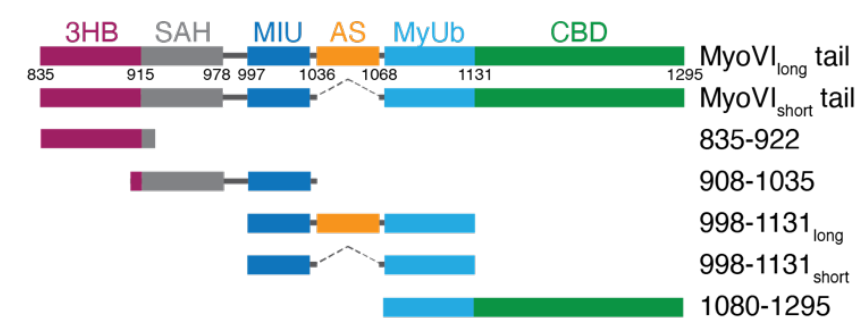

B

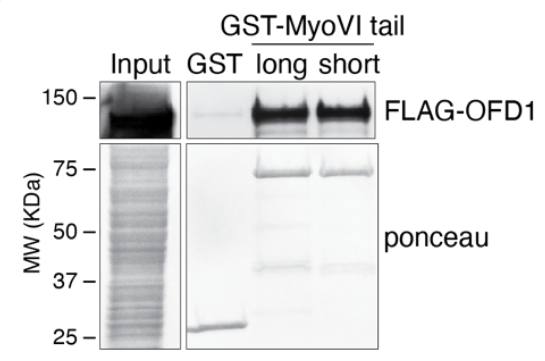

C

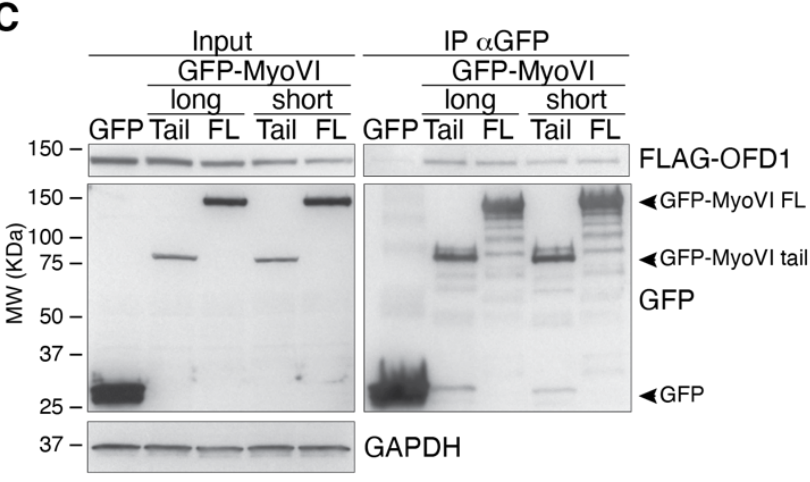

D

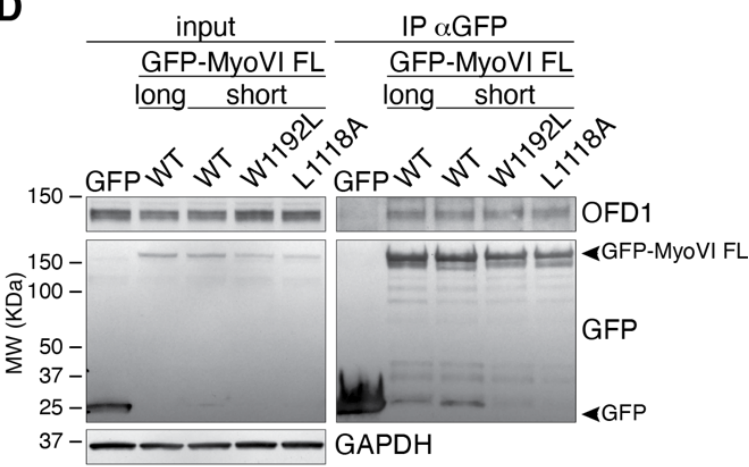

E

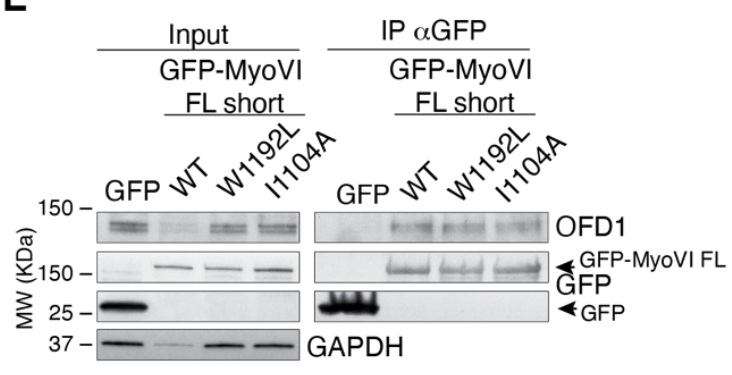

F

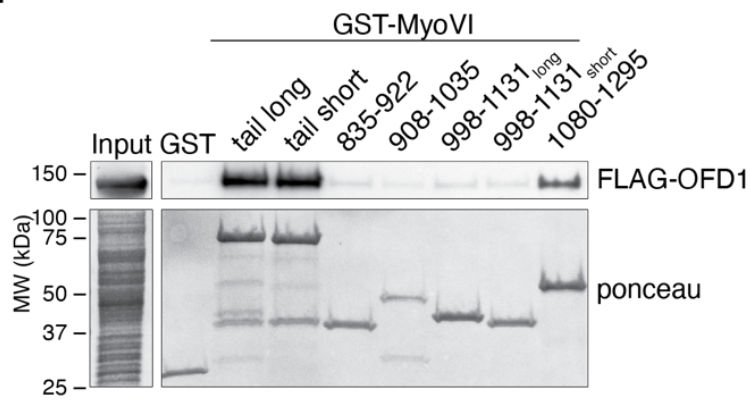




\section{Supplementary Figure 2: Characterization of the myosin VI minimal region of binding to OFD1.}

(A) A scheme of the structure and domain organisation of myosin VI. The tail domain is composed of a three-helix bundle (3HB), a single alpha helix (SAH), two ubiquitin binding regions (MIU = motif interacting with ubiquitin; $\mathrm{MyUb}=$ Myosin VI ubiquitin binding domain), and a cargo binding domain (CBD). Between the MIU and the MyUb, an alternative spliced region (AS, in orange) is present in myosin $\mathrm{VI}_{\text {long }}$ isoform, while it is absent in the myosin $\mathrm{VI}_{\text {short }}$ isoform.

(B) GST pulldown assay using the indicated myosin VI tail (835-1295) constructs or GST alone as control and lysates from HEK293T cells transfected with Flag-OFD1 construct. IB was performed with anti-Flag antibody. Ponceau staining as indicated.

(C) Total lysates from HEK293T transfected with Flag-OFD1 and the indicated GFP-myosin VI constructs (or GFP as control) were IP with anti-GFP antibody-conjugated beads. IB was performed with anti-OFD1 and anti-GFP antibodies. Anti-GAPDH was used as loading control. $\mathrm{FL}=$ full length.

(D-E) Total lysates from HEK293T transfected with GFP (as control) or GFP-myosin VI constructs containing the indicated single-point mutations were IP with anti-GFP antibodyconjugated beads. IB was performed with anti-OFD1 and anti-GFP antibodies. Anti-GAPDH was used as loading control. FL = full length.

(F) GST pulldown assay using the indicated myosin VI constructs or GST alone as control and lysates from HEK293T cells transfected with Flag-OFD1 construct. IB was performed with antiFlag antibody. Ponceau staining as indicated. 
A

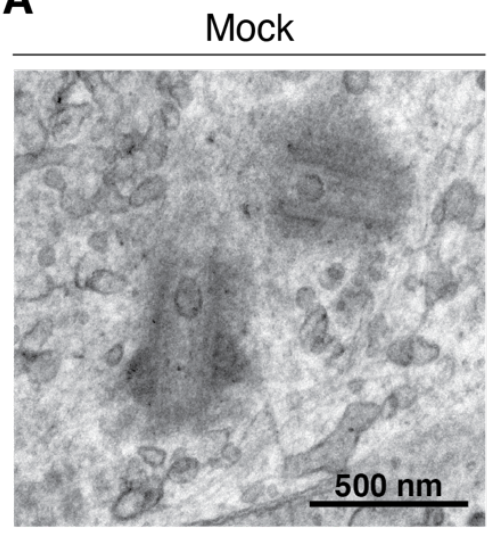

MyoVI KD

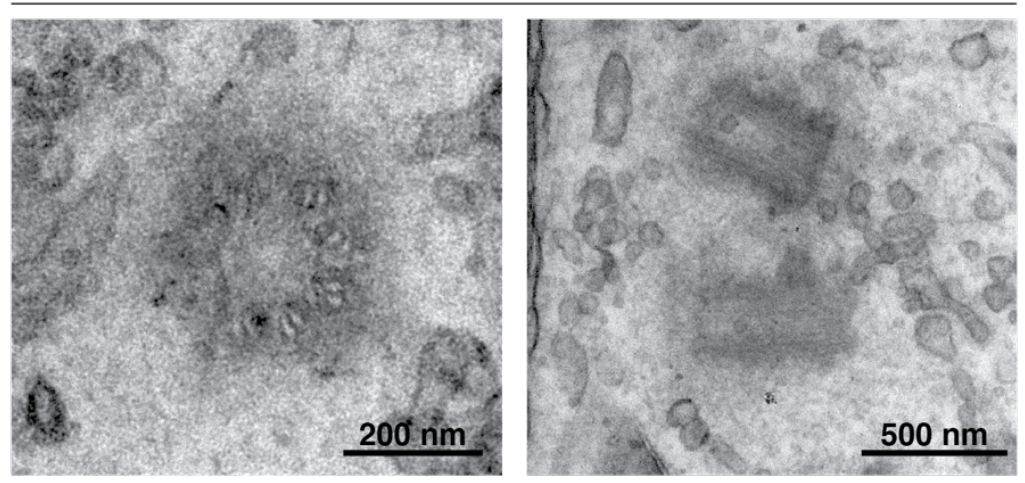

B

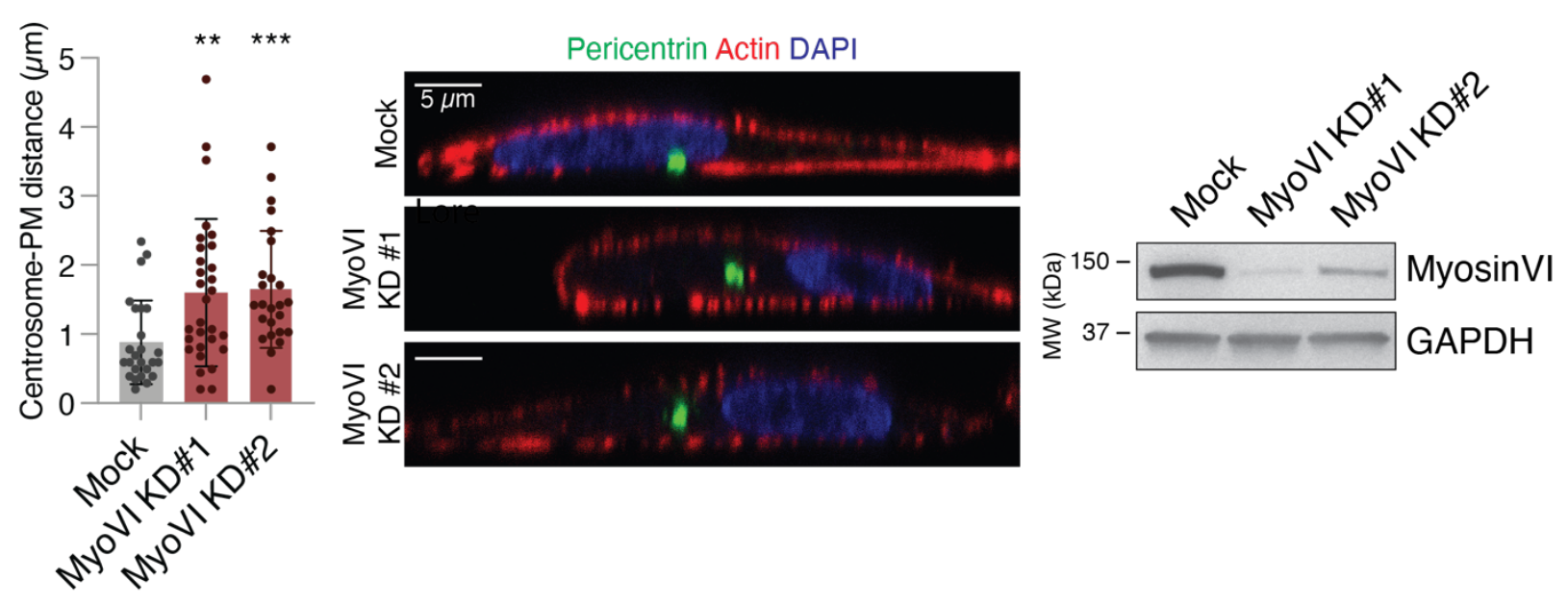

\section{Supplementary Figure 3: Myosin VI depletion does not affect centrioles ultrastructure.}

(A) Transmitted electron microscopy (TEM) analysis of centriole structure in hTERT-RPE1 control and myosin VI-depleted cells. Representative images are shown, scale bar as indicated.

(B) Depletion of myosin VI leads to displacement of the centrosomes from the cell cortex. hTERTRPE1 cells were transfected with the indicated siRNA oligos and, after 96 hours, were stained with anti-pericentrin to mark centrioles, phalloidin-TRITC to mark cortical actin, and DAPI to mark the nuclei. Left, the distance of the centrosome from the plasma membrane was calculated using ImageJ from XZ-axis images of the cells. The mean distance \pm SD is reported. $n=2$ independent experiments. $\mathrm{N}=25-30$ cells/condition were counted. $* * \mathrm{P}<0,005 ; * * * \mathrm{P}<0,001$ by Kruskal-Wallis test. Centre, representative images are shown; scale bar, $5 \mu \mathrm{m}$. Increased distance between centrioles and nuclear membrane is evident. Right, IB analysis showing myosin VI depletion. 
A

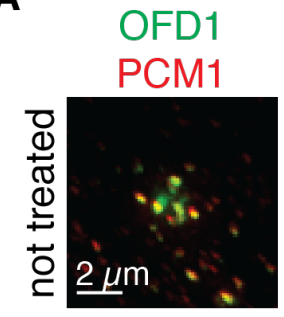

OFD1

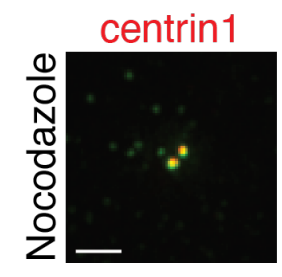

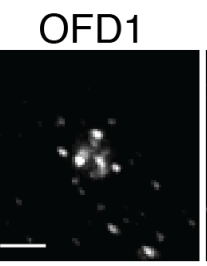

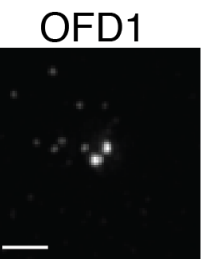

PCM1

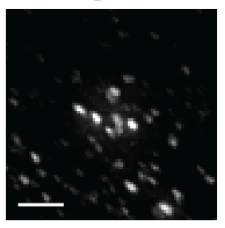

centrin1

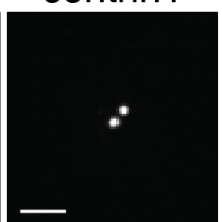

B

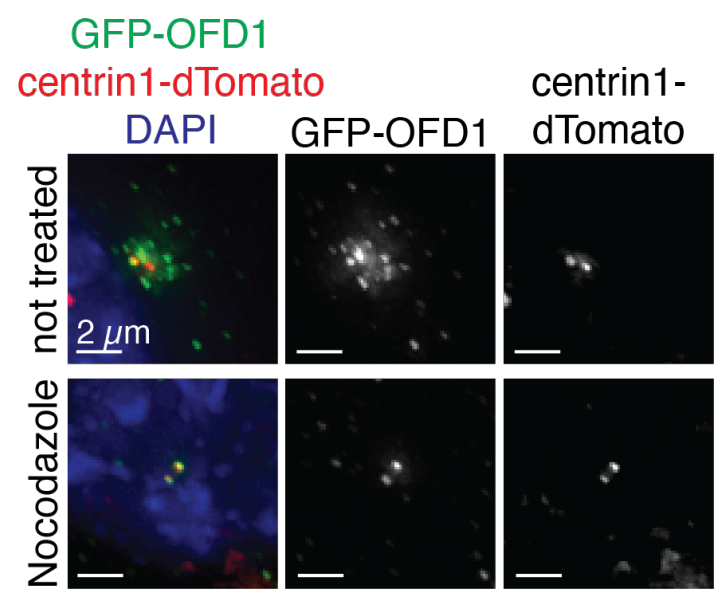

Supplementary Figure 4: Nocodazole treatment leads to the dispersion of OFD1 satellite pool.

(A) hTERT-RPE1 cells were treated with nocodazole at $6 \mu \mathrm{g} / \mathrm{ml}$ for 1 hour prior fixation to scatter the centriolar satellites and remove OFD1 satellites pool. Cells were immunostained with the antiOFD1 antibody and the indicated markers for centriolar satellites (anti-PCM1) and centrioles (anticentrin1). Representative images are shown; scale bar, $2 \mu \mathrm{m}$.

(B) Effect of nocodazole treatment on GFP-OFD1 localisation in hTERT-RPE cells stably expressing GFP-OFD1 and centrin1-dTomato, used in FRAP experiments shown in Figure 4. Representative images are shown; scale bar, $2 \mu \mathrm{m}$. 
A
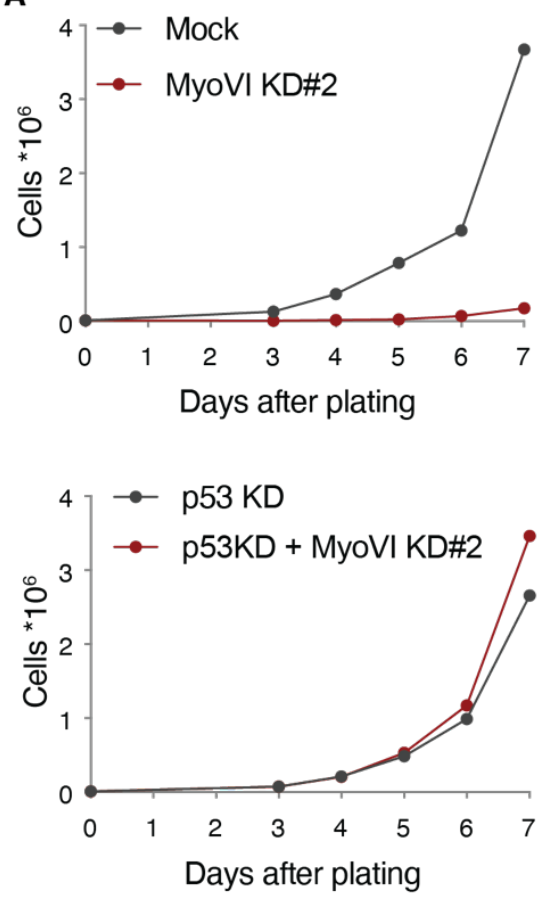

B

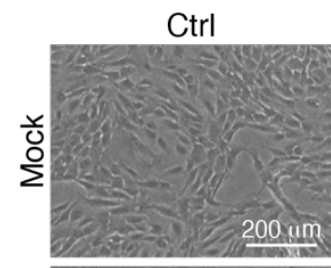

siRNA p53
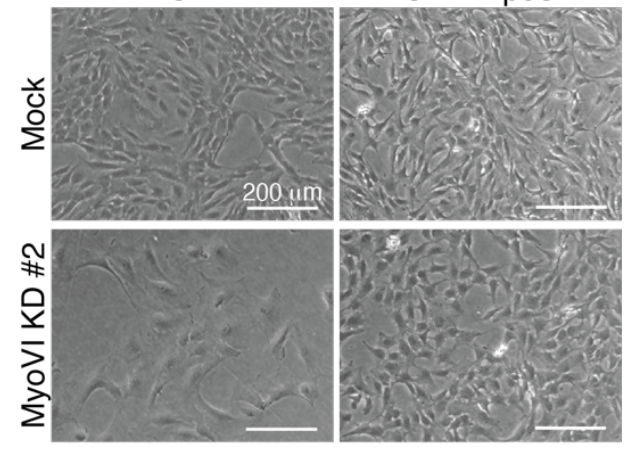

C

SiRNA p53: $-\quad-\quad-\quad+\quad+\quad+$ siRNA MyoVI: $-{ }^{-} \# 1 \quad \# 2 \quad-\quad \# 1$ \#2

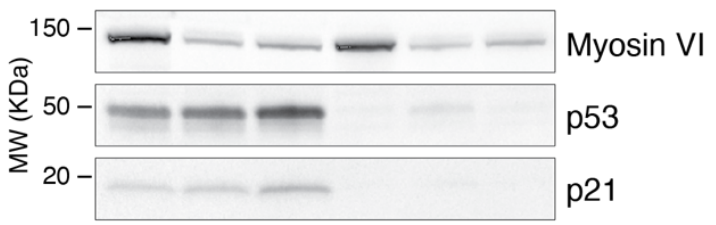

D

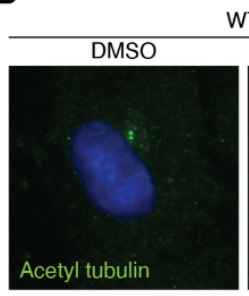

WT

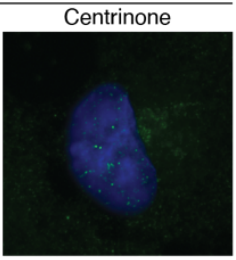

53BP1 K/O
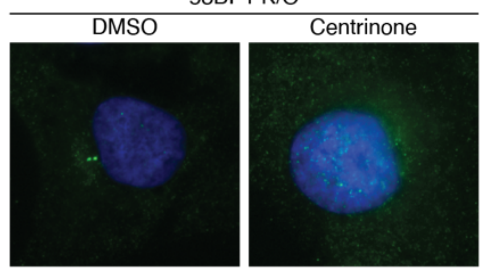

$\mathbf{F}$

hTERT-RPE WT

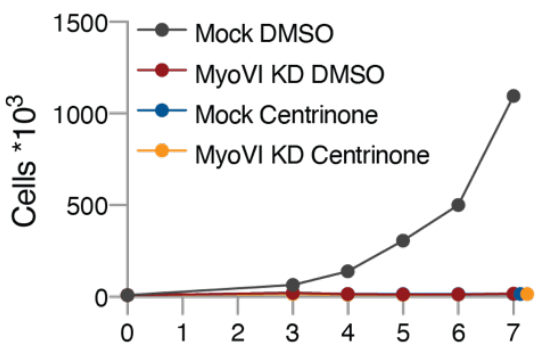

Days after plating
E

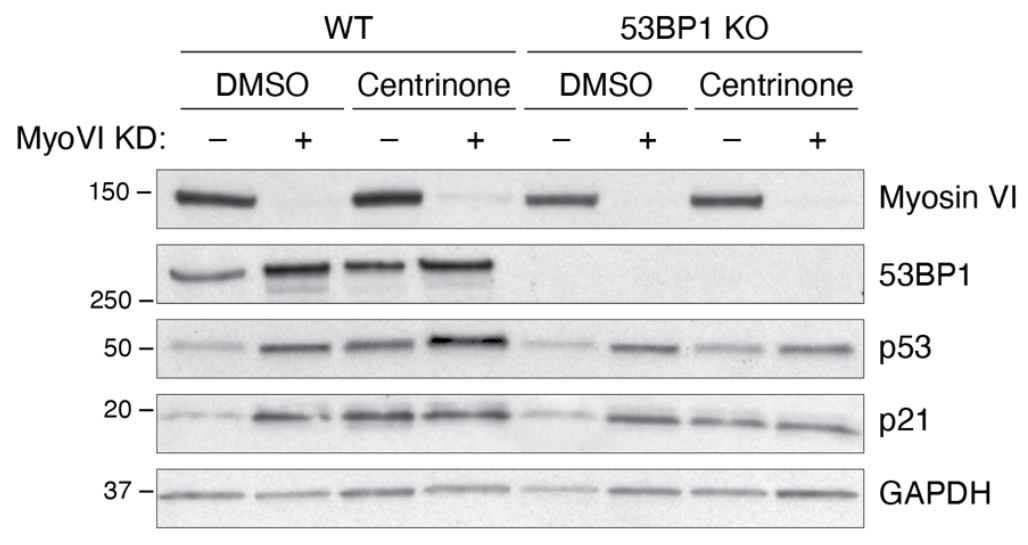

hTERT-RPE 53BP1 K/O

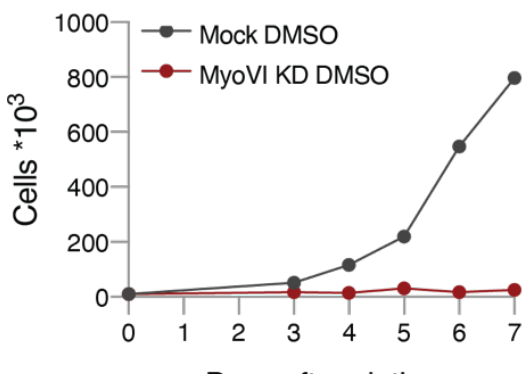

Days after plating

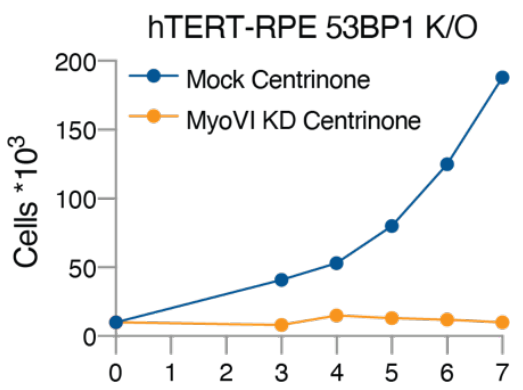

Days after plating 


\section{Supplementary Figure 5: p53 activation in myosin VI-depleted cells is not due to its effect on centrioles.}

(A-C) Severe proliferation impairment in myosin VI-depleted RPE1 cells is reproducible using a second siRNA oligo against myosin VI (KD\#2).

(A) Growth curve of hTERT-RPE1 cells transfected with a second myosin VI siRNA oligo +/p53 siRNA oligo. A representative plot of three independent experiments is shown.

(B) Representative bright field images of cells treated with the indicated p53 and myosin VI siRNAs.

(C) IB analysis of control and myosin VI-depleted hTERT-RPE cells with anti-myosin VI, antip53 and anti-p21 antibodies. Anti-GAPDH was used as loading control.

(D) hTERT-RPE1 wild-type or 53BP1 KO cells were treated with centrinone or DMSO (as control) and immunostained with anti-acetylated tubulin antibody and DAPI to verify the presence or absence of centrioles.

(E) Analysis of hTERT-RPE wild-type or 53BP1 KO cells transfected with myosin VI siRNA and treated with centrinone or DMSO (as control) by IB, with anti-myosin VI, anti-53BP1, anti-p53 and anti-p21 antibodies. Anti-GAPDH was used as loading control.

(F) Growth curves of hTERT-RPE1 wild-type or 53BP1 KO cells transfected with myosin VI siRNA and treated with centrinone or DMSO. Representative plots of three independent experiments are shown. 
bioRxiv preprint doi: https://doi.org/10.1101/2021.06.18.448975Ḧth version posted June 19, 2021. The copyright holder for this preprint (which was not certified by peer review) is the author/funder. All rights reserved. No reuse qllowed withloukparbeiss fopeptides

Desmoplakin OS=Homo sapiens GN=DSP PE=1 SV=3

Cluster of Isoform 2 of Nuclear mitotic apparatus protein 1 OS=Homo sapiens GN=NUMA1 (Q14980-2)

Periplakin OS=Homo sapiens GN=PPL PE=1 SV=4

Cluster of Unconventional myosin-VI (Fragment) OS=Homo sapiens GN=MYO6 PE=2 SV=1 (Q5JVMO)

Cluster of Spectrin beta chain, non-erythrocytic 2 OS=Homo sapiens GN=SPTBN2 PE=1 SV=3 (SPTN2_HUMAN)

Spectrin alpha chain, non-erythrocytic $1 \mathrm{OS}=$ Homo sapiens GN=SPTAN1 PE=1 SV=3

Plectin OS=Homo sapiens GN=PLEC (Q15149-4)

DNA-dependent protein kinase catalytic subunit $O S=$ Homo sapiens $G N=P R K D C P E=1 S V=3$

Cluster of Isoform 3 of PERQ amino acid-rich with GYF domain-containing protein 2 OS=Homo sapiens GN=GIGYF2 (Q6Y7W6-4)

Cluster of Solute carrier family 12 member 4 OS=Homo sapiens GN=SLC12A4 PE=1 SV=2 (S12A4_HUMAN)

Pericentrin OS=Homo sapiens $G N=P C N T P E=1 S V=4$

Myosin-9 OS=Homo sapiens GN=MYH9 PE=1 SV=4

Nuclear pore complex protein Nup155 OS=Homo sapiens GN=NUP155 PE=1 SV=1

Oral-facial-digital syndrome 1 protein $O S=$ Homo sapiens GN=OFD1 $P E=1 \mathrm{SV}=1$

Splicing factor, proline- and glutamine-rich $O S=$ Homo sapiens $G N=S F P Q P E=1 S V=2$

E3 ubiquitin-protein ligase DTX3L OS=Homo sapiens GN=DTX3L PE=1 SV=1

DNA replication licensing factor MCM4 OS=Homo sapiens $G N=M C M 4 P E=1 S V=5$

GRIP and coiled-coil domain-containing protein $2 \mathrm{OS}=$ Homo sapiens $\mathrm{GN}=\mathrm{GCC} 2 \mathrm{PE}=1 \mathrm{SV}=4$

Myosin-10 OS=Homo sapiens GN=MYH10 PE=1 SV=3

Isoform 2 of Poly [ADP-ribose] polymerase 9 OS=Homo sapiens GN=PARP9

Cluster of Isoform 2 of LisH domain and HEAT repeat-containing protein KIAA1468 OS=Homo sapiens GN=KIAA1468 (Q9P260-2)

Cluster of Protein enabled homolog OS=Homo sapiens GN=ENAH PE=1 SV=2 (ENAH_HUMAN)

Nuclear pore complex protein Nup205 OS=Homo sapiens GN=NUP205 PE=1 SV=3

Spectrin beta chain, non-erythrocytic $1 \mathrm{OS}=$ Homo sapiens $\mathrm{GN}=\mathrm{SPTBN} 1 \mathrm{PE}=1 \mathrm{SV}=2$

DNA replication licensing factor $M C M 6$ OS=Homo sapiens $G N=M C M 6 P E=1 S V=1$

Golgi integral membrane protein 4 OS=Homo sapiens $G N=G O L I M 4 P E=1 S V=1$

Cluster of Mitogen-activated protein kinase kinase kinase kinase 4 OS=Homo sapiens GN=MAP4K4 PE=2 SV=1 (G3XAA2)

Eukaryotic translation initiation factor 3 subunit $A$ OS=Homo sapiens $G N=E I F 3 A P E=1 S V=1$

Rab11 family-interacting protein $1 \mathrm{OS}=$ Homo sapiens $\mathrm{GN}=\mathrm{RAB} 11 \mathrm{FIP} 1 \mathrm{PE}=1 \mathrm{SV}=2$

Nuclear migration protein nudC OS=Homo sapiens $G N=N U D C P E=1 \mathrm{SV}=1$

Cingulin OS=Homo sapiens GN=CGN PE=1 SV=2

Calcineurin-binding protein cabin-1 OS=Homo sapiens $G N=C A B I N 1 P E=1 S V=1$

Oxysterol-binding protein-related protein $11 \mathrm{OS}=$ Homo sapiens $\mathrm{GN}=\mathrm{OSBPL11} \mathrm{PE}=1 \mathrm{SV}=2$

Neurabin-2 OS=Homo sapiens GN=PPP1R9B PE=1 SV=2

Oxysterol-binding protein-related protein 9 OS=Homo sapiens GN=OSBPL9 PE=1 SV=2

Complement $\mathrm{C} 3$ OS=Homo sapiens $\mathrm{GN}=\mathrm{C} 3 \mathrm{PE}=1 \mathrm{SV}=2$

Acetyl-CoA acetyltransferase, mitochondrial OS=Homo sapiens $\mathrm{GN}=\mathrm{ACAT1} P \mathrm{PE}=1 \mathrm{SV}=1$

Mitochondrial inner membrane protein $O S=$ Homo sapiens $G N=I M M T P E=1 S V=1$

Ubinuclein-2 OS=Homo sapiens GN=UBN2 PE=1 SV=2

Dermcidin OS=Homo sapiens GN=DCD PE $=1 \mathrm{SV}=2$

Serine/threonine-protein kinase $\mathrm{N} 1 \mathrm{OS}=$ Homo sapiens $\mathrm{GN}=\mathrm{PKN} 1 \mathrm{PE}=1 \mathrm{SV}=2$

AMP deaminase 2 OS=Homo sapiens $G N=A M P D 2 P E=1 S V=2$

ADP-ribosylation factor $3 \mathrm{OS}=$ Homo sapiens $\mathrm{GN}=\mathrm{ARF} 3 \mathrm{PE}=1 \mathrm{SV}=2$

Neurabin- 1 OS=Homo sapiens GN=PPP1R9A PE=2 SV=1

Centromere protein $\mathrm{F}$ OS=Homo sapiens $\mathrm{GN}=\mathrm{CENPF} P E=1 \mathrm{SV}=2$

Translocon-associated protein subunit delta OS=Homo sapiens $\mathrm{GN}=\mathrm{SSR} 4 \mathrm{PE}=1 \mathrm{SV}=1$

DNA replication licensing factor $M C M 7 O S=$ Homo sapiens $G N=M C M 7 P E=1 \quad S V=4$

Pre-B-cell leukemia transcription factor $1 \mathrm{OS}=$ Homo sapiens $\mathrm{GN}=\mathrm{PBX} 1 \mathrm{PE}=1 \mathrm{SV}=1$

Tropomodulin- 3 OS=Homo sapiens GN=TMOD $3 \mathrm{PE}=1 \mathrm{SV}=1$

Calmodulin OS=Homo sapiens GN=CALM1 PE=1 SV=2

Isoform Short of Probable global transcription activator SNF2L2 OS=Homo sapiens GN=SMARCA2

4F2 cell-surface antigen heavy chain OS=Homo sapiens $G N=S L C 3 A 2 P E=1 S V=3$

Protein HIRA OS=Homo sapiens GN=HIRA PE=1 SV=2

$\mathrm{LIM}$ domain only protein $7 \mathrm{OS}=$ Homo sapiens $\mathrm{GN}=\mathrm{LMO} 7 \mathrm{PE}=1 \mathrm{SV}=3$

Eukaryotic translation initiation factor 3 subunit $C$ OS=Homo sapiens $G N=E I F 3 C P E=1 S V=1$

Structural maintenance of chromosomes protein $3 \mathrm{OS}=$ Homo sapiens $\mathrm{GN}=\mathrm{SMC3} P E=1 \mathrm{SV}=2$

Drebrin-like protein OS=Homo sapiens $\mathrm{GN}=\mathrm{DBNL} P E=2 \mathrm{SV}=1$

Nucleoprotein TPR OS=Homo sapiens GN=TPR PE=1 SV=3

RAB6-interacting golgin $O S=$ Homo sapiens $G N=G O R A B P E=1 S V=1$

$40 \mathrm{~S}$ ribosomal protein $\mathrm{S} 18 \mathrm{OS}=\mathrm{Homo}$ sapiens $\mathrm{GN}=\mathrm{RPS} 18 \mathrm{PE}=1 \mathrm{SV}=3$

Cofilin-1 OS=Homo sapiens GN=CFL1 PE=1 SV=3

Cleavage and polyadenylation-specificity factor subunit $6 \mathrm{OS}=$ Homo sapiens $\mathrm{GN}=\mathrm{CPSF} 6 \mathrm{PE}=2 \mathrm{SV}=1$

DNA replication licensing factor MCM2 (Fragment) OS=Homo sapiens GN=MCM2 PE=3 SV=1

DSP

NUMA1

PEPL

MYO6

SPTBN2

SPTAN1

PLEC

PRKDC

GIGYF2

SLC12A4

PCNT

MYH9

NUP155

OFD1

SFPQ

DTX3L

MCM4

GCC2

MYH10

PARP9

KIAA1468

ENAH

NUP205

SPTB2

MCM6

GOLI4

MAP4K4

EIF3A

RAB11FIP1

NUDC

CGN

CABIN

OSBPL11

PPP1R9B

OSBPL9

C3

ACAT1

IMMT

UBN2

DCD

PKN1

AMPD2

ARF3

PPP1R9A

CENPF

SSR4

MCM7

PBX1

TMOD3

CALM1

SNF2L2

SLC3A2

HIRA

LMO7

EIF3C

SMC3

DBNL

TPR

GORAB

RPS18

CFL1

CPSF6

$\mathrm{MCM} 2$

IP_ctrl IP_myosin VI 


\begin{tabular}{|c|c|c|c|}
\hline & & IP_ctrl & IP_myosin VI \\
\hline Plectin OS=Homo sapiens GN=PLEC (Q15149-4) & PLEC & 0 & 218 \\
\hline Desmoplakin OS=Homo sapiens GN=DSP PE $=1 \mathrm{SV}=3$ & DSP & 22 & 201 \\
\hline Periplakin OS=Homo sapiens GN=PPL PE=1 SV=4 & PEPL & 4 & 142 \\
\hline Cluster of Isoform 2 of Nuclear mitotic apparatus protein 1 OS=Homo sapiens GN=NUMA1 (Q14980-2) & NUMA & 0 & 141 \\
\hline DNA-dependent protein kinase catalytic subunit $\mathrm{OS}=$ Homo sapiens GN=PRKDC PE=1 SV=3 & PRKDC & 0 & 93 \\
\hline Cluster of Unconventional myosin-VI (Fragment) OS=Homo sapiens GN=MYO6 PE=2 SV=1 (Q5JVM0) & MYO6 & 0 & 86 \\
\hline Myosin-9 OS=Homo sapiens GN=MYH9 PE=1 SV=4 & MYH9 & 2 & 74 \\
\hline Cluster of Isoform 3 of PERQ amino acid-rich with GYF domain-containing protein 2 OS=Homo sapiens GN=GIGYF2 (Q6Y7W6-4) & GIGYF2 & 0 & 39 \\
\hline Cluster of Mitogen-activated protein kinase kinase kinase kinase 4 OS=Homo sapiens GN=MAP4K4 PE=2 SV=1 (G3XAA2) & MAP4K4 & 0 & 29 \\
\hline Neuroblast differentiation-associated protein AHNAK OS=Homo sapiens GN=AHNAK PE=1 SV=2 & AHNAK & 0 & 29 \\
\hline Cluster of Solute carrier family 12 member $4 \mathrm{OS}=$ Homo sapiens GN=SLC12A4 PE=1 SV=2 (S12A4_HUMAN) & SLC12A4 & 0 & 26 \\
\hline Cluster of Spectrin beta chain, non-erythrocytic 2 OS=Homo sapiens GN=SPTBN2 PE=1 SV=3 (SPTN2_HUMAN) & SPTBN2 & 0 & 25 \\
\hline Eukaryotic translation initiation factor 3 subunit A OS=Homo sapiens GN=EIF3A PE=1 SV=1 & EIF3A & 0 & 25 \\
\hline Spectrin alpha chain, non-erythrocytic 1 OS=Homo sapiens GN=SPTAN1 PE=1 SV=3 & SPTAN1 & 0 & 24 \\
\hline GRIP and coiled-coil domain-containing protein $2 \mathrm{OS}=$ Homo sapiens $\mathrm{GN}=\mathrm{GCC} 2 \mathrm{PE}=1 \mathrm{SV}=4$ & GCC2 & 0 & 22 \\
\hline Myosin-14 OS=Homo sapiens GN=MYH14 PE=1 SV=2 & MYH14 & 0 & 18 \\
\hline Splicing factor, proline- and glutamine-rich $\mathrm{OS}=$ Homo sapiens $\mathrm{GN}=\mathrm{SFPQ} P E=1 \mathrm{SV}=2$ & SFPQ & 0 & 16 \\
\hline Envoplakin OS=Homo sapiens GN=EVPL PE=1 SV=3 & EVPL & 0 & 16 \\
\hline Pericentrin OS=Homo sapiens GN=PCNT PE=1 SV=4 & PCNT & 0 & 16 \\
\hline Rab11 family-interacting protein $1 \mathrm{OS}=$ Homo sapiens $\mathrm{GN}=\mathrm{RAB} 11 \mathrm{FIP1} \mathrm{PE}=1 \mathrm{SV}=2$ & RAB11FIP1 & 0 & 16 \\
\hline E3 ubiquitin-protein ligase DTX3L OS=Homo sapiens GN=DTX3L PE=1 SV=1 & DTX3L & 0 & 15 \\
\hline Myosin-10 OS=Homo sapiens GN=MYH10 PE=1 SV=3 & MYH10 & 0 & 15 \\
\hline Nuclear migration protein nudC OS=Homo sapiens GN=NUDC PE=1 SV=1 & NUDC & 0 & 14 \\
\hline Cluster of Isoform 2 of LisH domain and HEAT repeat-containing protein KIAA1468 OS=Homo sapiens GN=KIAA1468 (Q9P260-2) & KIAA1468 & 0 & 12 \\
\hline Unconventional myosin-Va OS=Homo sapiens GN=MYO5A PE=2 SV=1 & MYO5A & 0 & 10 \\
\hline Protein FAM83H OS=Homo sapiens GN=FAM83H PE=1 SV=3 & FAM83H & 0 & 9 \\
\hline Isoform 2 of Poly [ADP-ribose] polymerase 9 OS=Homo sapiens GN=PARP9 & PARP9 & 0 & 8 \\
\hline Cingulin OS=Homo sapiens GN=CGN PE=1 SV=2 & CGN & 0 & 8 \\
\hline A-kinase anchor protein $9 \mathrm{OS}=$ Homo sapiens $\mathrm{GN}=\mathrm{AKAP9} P E=1 \mathrm{SV}=3$ & AKAP9 & 0 & 8 \\
\hline Cluster of Protein enabled homolog OS=Homo sapiens GN=ENAH PE=1 SV=2 (ENAH_HUMAN) & ENAH & 0 & 7 \\
\hline Nuclear pore complex protein Nup155 OS=Homo sapiens GN=NUP155 PE=1 SV=1 & NUP155 & 0 & 7 \\
\hline Tight junction protein ZO-2 OS=Homo sapiens GN=TJP2 PE=1 SV=2 & TJP2 & 0 & 7 \\
\hline Oral-facial-digital syndrome 1 protein OS=Homo sapiens GN=OFD1 PE=1 SV=1 & OFD1 & 0 & 6 \\
\hline Clathrin heavy chain 1 OS=Homo sapiens GN=CLTC PE=1 SV=5 & CLTC & 0 & 6 \\
\hline Tropomodulin-3 OS=Homo sapiens GN=TMOD3 PE=1 SV=1 & TMOD3 & 0 & 6 \\
\hline Serine/arginine repetitive matrix protein $2 \mathrm{OS}=$ Homo sapiens $\mathrm{GN}=\mathrm{SRRM} 2 \mathrm{PE}=1 \mathrm{SV}=2$ & SRRM2 & 0 & 5 \\
\hline Complement C3 OS=Homo sapiens GN=C3 PE=1 SV=2 & C3 & 0 & 5 \\
\hline Isoform 2 of RB1-inducible coiled-coil protein 1 OS=Homo sapiens GN=RB1CC1 & RB1CC1 & 0 & 5 \\
\hline Nuclear pore complex protein Nup205 OS=Homo sapiens GN=NUP205 PE=1 SV=3 & NUP205 & 0 & 5 \\
\hline Calmodulin OS=Homo sapiens GN=CALM1 PE=1 SV=2 & CALM1 & 0 & 5 \\
\hline Acetyl-CoA acetyltransferase, mitochondrial $\mathrm{OS}=$ Homo sapiens $\mathrm{GN}=\mathrm{ACAT} 1 \mathrm{PE}=1 \mathrm{SV}=1$ & ACAT1 & 0 & 5 \\
\hline Calmin OS=Homo sapiens GN=CLMN PE=1 SV=1 & CLMN & 0 & 5 \\
\hline Rootletin OS=Homo sapiens GN=CROCC PE=1 SV=1 & CROCC & 0 & 5 \\
\hline Oxysterol-binding protein-related protein $10 \mathrm{OS}=$ Homo sapiens $\mathrm{GN}=\mathrm{OSBPL10} \mathrm{PE}=1 \mathrm{SV}=2$ & OSBPL10 & 0 & 4 \\
\hline Integrin beta- $4 \mathrm{OS}=$ Homo sapiens $\mathrm{GN}=$ ITGB $4 \mathrm{PE}=1 \mathrm{SV}=5$ & ITGB4 & 0 & 3 \\
\hline Eukaryotic translation initiation factor 3 subunit G OS=Homo sapiens GN=EIF3G PE=1 SV=2 & EIF3G & 0 & 3 \\
\hline Serine/arginine repetitive matrix protein $1 \mathrm{OS}=$ Homo sapiens GN=SRRM1 PE=1 SV=2 & SRRM1 & 0 & 3 \\
\hline DNA repair protein RAD50 OS=Homo sapiens GN=RAD50 PE=1 SV=1 & RAD50 & 0 & 3 \\
\hline Pleckstrin homology-like domain family B member 2 OS=Homo sapiens GN=PHLDB2 PE=1 SV=2 & PHLDB2 & 0 & 3 \\
\hline Cytoplasmic dynein 1 heavy chain 1 OS=Homo sapiens GN=DYNC1H1 PE=1 SV=5 & DYNC1H1 & 0 & 3 \\
\hline Pleckstrin homology domain-containing family A member 7 OS=Homo sapiens GN=PLEKHA7 PE=2 SV=1 & PLEKHA7 & 0 & 3 \\
\hline Non-POU domain-containing octamer-binding protein OS=Homo sapiens GN=NONO PE=1 SV=4 & NONO & 0 & 2 \\
\hline 182 kDa tankyrase-1-binding protein OS=Homo sapiens GN=TNKS1BP1 PE=1 SV=4 & TNKS1BP1 & 0 & 2 \\
\hline CD109 antigen OS=Homo sapiens GN=CD109 PE=1 SV=2 & CD109 & 0 & 2 \\
\hline Fatty acid synthase $\mathrm{OS}=$ Homo sapiens $\mathrm{GN}=\mathrm{FASN} P E=1 \mathrm{SV}=3$ & FASN & 0 & 2 \\
\hline Isoform 2 of La-related protein 1 OS=Homo sapiens GN=LARP1 & LARP1 & 0 & 2 \\
\hline Isoform 2 of Serine/threonine-protein kinase TAO2 OS=Homo sapiens GN=TAOK2 & TAOK2 & 0 & 2 \\
\hline Kinesin-like protein KIF14 OS=Homo sapiens GN=KIF14 PE=1 SV=1 & KIF14 & 0 & 2 \\
\hline Ubiquitin-40S ribosomal protein S27a OS=Homo sapiens GN=RPS27A PE=1 SV=2 & RPS27A & 0 & 2 \\
\hline
\end{tabular}


Plectin OS=Homo sapiens GN=PLEC (Q15149-4)

Cluster of Isoform 2 of Nuclear mitotic apparatus protein 1 OS=Homo sapiens GN=NUMA1 (Q14980-2)

Periplakin OS=Homo sapiens GN=PPL PE=1 SV=4

Myosin-9 OS=Homo sapiens GN=MYH9 PE=1 SV=4

Cluster of Unconventional myosin-VI (Fragment) OS=Homo sapiens GN=MYO6 PE=2 SV=1 (Q5JVM0)

DNA-dependent protein kinase catalytic subunit OS=Homo sapiens GN=PRKDC PE=1 SV=3

Oral-facial-digital syndrome 1 protein $O S=H o m o$ sapiens $G N=O F D 1 P E=1$ SV=1

Cluster of Solute carrier family 12 member 4 OS=Homo sapiens GN=SLC12A4 PE=1 SV=2 (S12A4_HUMAN)

E3 ubiquitin-protein ligase DTX3L OS=Homo sapiens GN=DTX3L PE=1 SV=1

Cluster of Mitogen-activated protein kinase kinase kinase kinase 4 OS=Homo sapiens GN=MAP4K4 PE=2 SV=1 (G3XAA2)

Splicing factor, proline- and glutamine-rich OS=Homo sapiens GN=SFPQ PE=1 SV=2

GRIP and coiled-coil domain-containing protein 2 OS=Homo sapiens GN=GCC2 PE=1 SV=4

Isoform 2 of Poly [ADP-ribose] polymerase 9 OS=Homo sapiens GN=PARP9

Nuclear migration protein nudC OS=Homo sapiens GN=NUDC PE=1 SV=1

Cluster of Protein enabled homolog OS=Homo sapiens GN=ENAH PE=1 SV=2 (ENAH_HUMAN)

Cluster of Spectrin beta chain, non-erythrocytic $2 \mathrm{OS}=$ Homo sapiens GN=SPTBN2 PE=1 SV=3 (SPTN2 HUMAN)

Neurabin -2 OS=Homo sapiens GN=PPP1R9B PE $=1 \mathrm{SV}=2$

Eukaryotic translation initiation factor 3 subunit $A$ OS=Homo sapiens $G N=E I F 3 A P E=1 S V=1$

Serine/arginine repetitive matrix protein $2 \mathrm{OS}=$ Homo sapiens $\mathrm{GN}=\mathrm{SRRM} 2 \mathrm{PE}=1 \mathrm{SV}=2$

Envoplakin OS=Homo sapiens GN=EVPL PE $=1 \mathrm{SV}=3$

Integrin beta- 4 OS=Homo sapiens $G N=I T G B 4 P E=1 S V=5$

$4 F 2$ cell-surface antigen heavy chain $\mathrm{OS}=$ Homo sapiens $\mathrm{GN}=\mathrm{SLC} 3 \mathrm{~A} 2 \mathrm{PE}=1 \mathrm{SV}=3$

Pericentrin OS=Homo sapiens GN=PCNT PE=1 SV=4

Nuclear pore complex protein Nup155 OS=Homo sapiens GN=NUP155 PE=1 SV=1

Oxysterol-binding protein-related protein $10 \mathrm{OS}=$ Homo sapiens $\mathrm{GN}=\mathrm{OSBPL10} P E=1 \mathrm{SV}=2$

Protein HIRA OS=Homo sapiens GN=HIRA PE=1 SV=2

Mitochondrial inner membrane protein OS=Homo sapiens $G N=I M M T P E=1 S V=1$

Non-POU domain-containing octamer-binding protein OS=Homo sapiens GN=NONO PE=1 SV=4

Oxysterol-binding protein-related protein 9 OS=Homo sapiens GN=OSBPL9 PE=1 SV=2

DAZ-associated protein $1 \mathrm{OS}=$ Homo sapiens $\mathrm{GN}=\mathrm{DAZAP} 1 \mathrm{PE}=1 \mathrm{SV}=1$

Spectrin alpha chain, non-erythrocytic $1 \mathrm{OS}=$ Homo sapiens $G N=S P T A N 1 P E=1 S V=3$

Rab11 family-interacting protein $1 \mathrm{OS}=$ Homo sapiens $\mathrm{GN}=\mathrm{RAB} 11 \mathrm{FIP} 1 \mathrm{PE}=1 \mathrm{SV}=2$

Myosin-10 OS=Homo sapiens GN=MYH10 PE=1 SV=3

Cingulin $\mathrm{OS}=$ Homo sapiens $\mathrm{GN}=\mathrm{CGN} P \mathrm{PE}=1 \mathrm{SV}=2$

Clathrin heavy chain $1 \mathrm{OS}=$ Homo sapiens $\mathrm{GN}=\mathrm{CLTC} P E=1 \mathrm{SV}=5$

CDK5 regulatory subunit-associated protein 2 OS=Homo sapiens GN=CDK5RAP2 PE $=1 \mathrm{SV}=5$

DNA replication licensing factor MCM4 OS=Homo sapiens $G N=M C M 4 P E=1 S V=5$

Elongation factor 1-alpha $1 \mathrm{OS}=$ Homo sapiens $\mathrm{GN}=\mathrm{EEF} 1 \mathrm{~A} 1 \mathrm{PE}=1 \mathrm{SV}=1$

LIM domain only protein $7 \mathrm{OS}=$ Homo sapiens $\mathrm{GN}=\mathrm{LMO} 7 \mathrm{PE}=1 \mathrm{SV}=3$

Cytochrome b-c1 complex subunit 2, mitochondrial OS=Homo sapiens GN=UQCRC2 PE=1 SV=3

Sarcoplasmic/endoplasmic reticulum calcium ATPase 2 OS=Homo sapiens GN=ATP2A2 PE=1 SV=1

Sulfide:quinone oxidoreductase, mitochondrial $O S=$ Homo sapiens $G N=S Q R D L P E=1 S V=1$

Neuroblast differentiation-associated protein AHNAK OS=Homo sapiens GN=AHNAK PE=1 SV=2

Myosin-14 OS=Homo sapiens GN=MYH14 PE=1 SV=2

Protein FAM83H OS=Homo sapiens GN=FAM83H PE $=1 \mathrm{SV}=3$

A-kinase anchor protein 9 OS=Homo sapiens $G N=A K A P 9 P E=1 S V=3$

Tight junction protein ZO-2 OS=Homo sapiens GN=TJP2 PE=1 SV=2

Tropomodulin- 3 OS=Homo sapiens GN=TMOD3 PE=1 SV=1

Complement C3 OS=Homo sapiens $\mathrm{GN}=\mathrm{C} 3 \mathrm{PE}=1 \mathrm{SV}=2$

Isoform 2 of RB1-inducible coiled-coil protein 1 OS=Homo sapiens GN=RB1CC1

Nuclear pore complex protein Nup205 OS=Homo sapiens GN=NUP205 PE=1 SV=3

Eukaryotic translation initiation factor 3 subunit $G$ OS=Homo sapiens $G N=E I F 3 G \quad P E=1 S V=2$

Serine/arginine repetitive matrix protein $1 \mathrm{OS}=$ Homo sapiens $\mathrm{GN}=\mathrm{SRRM} 1 \mathrm{PE}=1 \mathrm{SV}=2$

DNA repair protein RAD50 OS=Homo sapiens $G N=R A D 50$ PE=1 SV=1

Actin, cytoplasmic 2 OS=Homo sapiens $\mathrm{GN}=\mathrm{ACTG} 1 \mathrm{PE}=1 \mathrm{SV}=1$

DNA replication licensing factor $\mathrm{MCM} 6 \mathrm{OS}=$ Homo sapiens $\mathrm{GN}=\mathrm{MCM} 6 \mathrm{PE}=1 \mathrm{SV}=1$

Dermcidin OS=Homo sapiens $\mathrm{GN}=\mathrm{DCD} P E=1 \mathrm{SV}=2$

Eukaryotic translation initiation factor 3 subunit $C O S=$ Homo sapiens $G N=E I F 3 C P E=1 S V=1$

Eukaryotic translation initiation factor 3 subunit $B$ OS=Homo sapiens $G N=E I F 3 B P E=1 S V=3$

Erlin-2 OS=Homo sapiens GN=ERLIN2 PE=1 SV=1

ORM1-like protein $1 \mathrm{OS}=$ Homo sapiens $\mathrm{GN}=\mathrm{ORMDL} 1 \mathrm{PE}=2 \mathrm{SV}=1$

Nuclear pore complex protein Nup93 OS=Homo sapiens GN=NUP93 PE=1 SV=2

Prostaglandin $\mathrm{F} 2$ receptor negative regulator OS=Homo sapiens $\mathrm{GN}=\mathrm{PTGFRN} P E=1 \mathrm{SV}=2$

Actin-like protein $6 \mathrm{~A}$ OS=Homo sapiens $\mathrm{GN}=\mathrm{ACTL} 6 \mathrm{~A} P E=1 \mathrm{SV}=1$

$60 S$ ribosomal protein $L 23$ OS=Homo sapiens $G N=R P L 23 P E=1 S V=1$

Rho guanine nucleotide exchange factor 2 OS=Homo sapiens GN=ARHGEF2 PE=1 SV=4

\begin{tabular}{|c|c|}
\hline entime & \begin{tabular}{|l|l|l|} 
IP_ctrl & IP_myosin VI \\
\end{tabular} \\
\hline
\end{tabular}

DSP

NUMA

PEPL

MYH9

MYO6

GIGYF2

PRKDC

OFD1

SLC12A4

DTX3L

MAP4K4

SFPQ

GCC2

PARP9

NUDC

ENAH

SPTBN2

NEB2

EIF3A

SRRM2

EVPL

ITGB4

SLC3A2

PCNT

NUP155

OSBPL10

HIRA

IMMT

NONO

OSBL9

DAZP1

SPTAN1

RAB11FIP1

MYH10

CGN

CLTC

CK5P2

MCM4

EEF1A1

LMO7

UQCRC2

ATP2A2

SQRDL

AHNAK

MYH14

FAM83H

AKAP9

TJP2

TMOD3

C3

RB1CC1

NUP205

EIF3G

SRRM1

RAD50

ACTG1

MCM6

DCD

EIF3C

EIF3B

ERLIN2

ORMDL1

NUP93

PTGFRN

ACTL6A

RPL23

ARHGEF2

(4)


bioRxiv preprint doi: https://doi.org/10.1101/2021.06.18.4083eశ-2; dbisfluexaibn posted June 19, 2021. The copyright holder for this prepriht

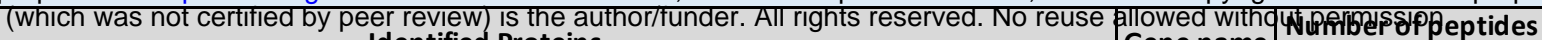
Identified Proteins

E3 ubiquitin-protein ligase DTX3L OS=Homo sapiens GN=DTX3L PE=1 SV=1

Poly [ADP-ribose] polymerase 9 OS=Homo sapiens $G N=P A R P 9 P E=1 S V=2$

Clathrin heavy chain 1 OS=Homo sapiens GN=CLTC PE $=1 \mathrm{SV}=5$

Splicing factor, proline- and glutamine-rich OS=Homo sapiens GN=SFPQ PE=1 SV=2

Nuclear mitotic apparatus protein $1 \mathrm{OS}=$ Homo sapiens $\mathrm{GN}=\mathrm{NUMA} 1 \mathrm{PE}=1 \mathrm{SV}=2$

Isoform 5 of Solute carrier family 12 member 4 OS=Homo sapiens GN=SLC12A4

Oral-facial-digital syndrome 1 protein $O S=H o m o$ sapiens $G N=O F D 1 P E=1$ SV=1

$T B C 1$ domain family member $2 B$ OS=Homo sapiens $G N=T B C 1 D 2 B P E=1 S V=2$

Protein transport protein Sec31A OS=Homo sapiens $G N=S E C 31 A P E=1 S V=1$

Isoform 2 of Drebrin-like protein OS=Homo sapiens $\mathrm{GN}=\mathrm{DBNL}$

Protein enabled homolog OS=Homo sapiens GN=ENAH PE=1 SV=2

Desmoplakin OS=Homo sapiens GN=DSP PE=1 SV=3

Isoform 2 of MAP7 domain-containing protein 2 OS=Homo sapiens GN=MAP7D2

Endoplasmin OS=Homo sapiens $\mathrm{GN}=\mathrm{HSP} 90 \mathrm{~B} 1 \mathrm{PE}=1 \mathrm{SV}=1$

Nucleolin OS=Homo sapiens GN=NCL PE=1 SV=3

DNA replication licensing factor MCM4 OS=Homo sapiens $\mathrm{GN}=\mathrm{MCM} 4 \mathrm{PE}=1 \mathrm{SV}=5$

Ubiquitin OS=Homo sapiens $\mathrm{GN}=\mathrm{UBB} \mathrm{PE}=2 \mathrm{SV}=1$

Heat shock protein HSP 90-beta OS=Homo sapiens $\mathrm{GN}=\mathrm{HSP90AB} 1 \mathrm{PE}=1 \mathrm{SV}=4$

Non-POU domain-containing octamer-binding protein $O S=$ Homo sapiens $G N=N O N O P E=1 S V=4$

TOM1-like protein $2 \mathrm{OS}=$ Homo sapiens $\mathrm{GN}=\mathrm{TOM} 1 \mathrm{~L} 2 \mathrm{PE}=1 \mathrm{SV}=1$

Toll-interacting protein OS=Homo sapiens $\mathrm{GN}=\mathrm{TOLLIP} \mathrm{PE}=1 \mathrm{SV}=1$

Protein HIRA OS=Homo sapiens $G N=H I R A ~ P E=1 S V=2$

Cingulin OS=Homo sapiens $\mathrm{GN}=\mathrm{CGN} P E=1 \mathrm{SV}=2$

$\mathrm{LisH}$ domain and HEAT repeat-containing protein KIAA1468 OS=Homo sapiens $\mathrm{GN}=\mathrm{KIAA} 1468 \mathrm{PE}=1 \mathrm{SV}=2$

Nuclear migration protein nudC OS=Homo sapiens $G N=N U D C P E=1 S V=1$

Serine/threonine-protein kinase $4 \mathrm{OS}=$ Homo sapiens $\mathrm{GN}=\mathrm{STK} 4 \mathrm{PE}=1 \mathrm{SV}=2$

Actin, cytoplasmic 1 OS=Homo sapiens GN=ACTB PE $=1 \mathrm{SV}=1$

Sodium/potassium-transporting ATPase subunit alpha-1 OS=Homo sapiens $G N=A T P 1 A 1 P E=1 S V=1$

14-3-3 protein epsilon OS=Homo sapiens $G N=Y W H A E P E=1 S V=1$

$40 \mathrm{~S}$ ribosomal protein $\mathrm{S} 3 \mathrm{OS}=$ Homo sapiens $\mathrm{GN}=\mathrm{RPS} 3 \mathrm{PE}=1 \mathrm{SV}=2$

Serine/threonine-protein kinase Nek1 OS=Homo sapiens GN=NEK1 PE=1 SV=2

Target of Myb protein $1 \mathrm{OS}=$ Homo sapiens $\mathrm{GN}=\mathrm{TOM} 1 \mathrm{PE}=1 \mathrm{SV}=2$

Rab11 family-interacting protein 1 OS=Homo sapiens GN=RAB11FIP1 PE=1 SV=3

PERQ amino acid-rich with GYF domain-containing protein 2 (Fragment) OS=Homo sapiens GN=GIGYF2 PE=1 SV=1

Homeobox-containing protein $1 \mathrm{OS}=$ Homo sapiens $\mathrm{GN}=\mathrm{HMBOX} 1 \mathrm{PE}=1 \mathrm{SV}=1$

Golgi integral membrane protein $4 \mathrm{OS}=$ Homo sapiens $\mathrm{GN}=\mathrm{GOLIM} 4 \mathrm{PE}=1 \mathrm{SV}=1$

DNA replication licensing factor $M C M 2$ (Fragment) $O S=$ Homo sapiens $G N=M C M 2 P E=1 S V=1$

DNA replication licensing factor MCM6 OS=Homo sapiens GN=MCM6 PE=1 SV=1

Annexin A2 OS=Homo sapiens $\mathrm{GN}=\mathrm{ANXA2} \mathrm{PE}=1 \mathrm{SV}=2$

Unconventional myosin-VI (Fragment) OS=Homo sapiens $\mathrm{GN}=\mathrm{MYO} 6 \mathrm{PE}=1 \mathrm{SV}=1$

Dipeptidyl peptidase $4 \mathrm{OS}=$ Homo sapiens $\mathrm{GN}=\mathrm{DPP} 4 \mathrm{PE}=1 \mathrm{SV}=2$

AMP deaminase 2 (Fragment) OS=Homo sapiens GN=AMPD2 PE=1 SV=1

Protein disulfide-isomerase $\mathrm{OS}=$ Homo sapiens $\mathrm{GN}=\mathrm{P} 4 \mathrm{HB} \mathrm{PE}=1 \mathrm{SV}=2$

Multiple $\mathrm{C} 2$ and transmembrane domain-containing protein $2 \mathrm{OS}=$ Homo sapiens $\mathrm{GN}=\mathrm{MCTP} 2 \mathrm{PE}=1 \mathrm{SV}=3$

Gene name

IP_ctrl|IP_myosin VI

DTX3L

PARP9

CLTC

SFPQ

NUMA

SLC12A4

OFD1

TBC1D2B

SEC31A

DBNL

ENAH

DSP

MAP7D2

HSP90B1

$\mathrm{NCL}$

MCM4

UBB

HSP90AB1

NONO

TOM1L2

TOLLIP

HIRA

CGN

KIAA1468

NUDC

STK4

ACTB

ATP1A1

YWHAE

RPS3

NEK1

TOM1

RAB11FIP1

GIGYF2

HMBOX1

GOLIM4

MCM2

MCM6

ANXA2

MYO6

DPP4

AMPD2

$\mathrm{P} 4 \mathrm{HB}$

MCTP2

SEC13

CALM1

Calmodulin OS=Homo sapiens $\mathrm{GN}=\mathrm{CALM} 1 \mathrm{PE}=1 \mathrm{SV}=2$

Nucleolar and coiled-body phosphoprotein $1 \mathrm{OS}=$ Homo sapiens GN=NOLC1 PE=1 SV=2

Oxysterol-binding protein-related protein $9 \mathrm{OS}=$ Homo sapiens $\mathrm{GN}=\mathrm{OSBPL9} \mathrm{PE}=1 \mathrm{SV}=2$

Alpha-actinin-4 OS=Homo sapiens GN=ACTN4 PE=1 SV=2

Desmoglein-1 OS=Homo sapiens GN=DSG1 PE=1 SV=2

PRKC apoptosis WT1 regulator protein OS=Homo sapiens $G N=P A W R P E=1 S V=1$

Dedicator of cytokinesis protein 7 OS=Homo sapiens $G N=D O C K 7 P E=1 S V=4$

Fructose-bisphosphate aldolase $O S=$ Homo sapiens $G N=A L D O A P E=1 S V=1$

Villin-1 OS=Homo sapiens GN=VIL1 PE=1 SV=4

Prohibitin OS=Homo sapiens GN=PHB PE=1 SV=1

$40 S$ ribosomal protein $\mathrm{S} 2$ (Fragment) OS=Homo sapiens $\mathrm{GN}=\mathrm{RPS} 2 \mathrm{PE}=1 \mathrm{SV}=1$

Neutral alpha-glucosidase $A B$ OS=Homo sapiens $G N=G A N A B P E=1 S V=3$

$60 S$ ribosomal protein $L 3$ OS=Homo sapiens $G N=R P L 3 P E=1 S V=2$

$10 \mathrm{kDa}$ heat shock protein, mitochondrial OS=Homo sapiens GN=HSPE1 PE=1 SV=1

$60 S$ ribosomal protein $L 5$ OS=Homo sapiens $G N=R P L 5 P E=1 S V=3$

Heat shock $70 \mathrm{kDa}$ protein $4 \mathrm{OS}=$ Homo sapiens $\mathrm{GN}=\mathrm{HSPA} 4 \mathrm{PE}=1 \mathrm{SV}=4$

Eukaryotic translation initiation factor 3 subunit $A$ OS=Homo sapiens $G N=E I F 3 A P E=1 S V=1$

CGG triplet repeat-binding protein $1 \mathrm{OS}=$ Homo sapiens $\mathrm{GN}=\mathrm{CGGBP} 1 \mathrm{PE}=1 \mathrm{SV}=2$

Lysine-specific demethylase $2 \mathrm{~A}$ OS=Homo sapiens $G N=K D M 2 A P E=1 \mathrm{SV}=3$

Coatomer subunit beta' OS=Homo sapiens $G N=C O P B 2 P E=1 S V=2$

AP-2 complex subunit beta OS=Homo sapiens $G N=A P 2 B 1 P E=1 S V=1$

Eukaryotic translation initiation factor 3 subunit $B$ OS=Homo sapiens GN=EIF3B PE=1 SV=3

40S ribosomal protein S19 OS=Homo sapiens GN=RPS19 PE=1 SV=2

Disintegrin and metalloproteinase domain-containing protein $10 \mathrm{OS}=$ Homo sapiens $\mathrm{GN}=\mathrm{ADAM} 10 \mathrm{PE}=1 \mathrm{SV}=1$

Uncharacterized protein OS=Homo sapiens GN=DCTN1 PE=1 SV=1

NOLC1

OSBPL9

ACTN4

DSG1

PAWR

DOCK7

ALDOA

VIL1

PHB

RPS2

GANAB

RPL3

HSPE1

RPL5

HSPA4

EIF3A

CGGBP1

KDM2A

COPB2

AP2B1

EIF3B

RPS19

ADAM10

DCTN

Exportin-2 OS=Homo sapiens GN=CSE1L PE $=1 \mathrm{SV}=3$

CSE1L 


\section{Methods}

\section{Constructs}

pGEX-myosin VI tail (835-1295) and pEGFP-myosin VI full-length (FL) constructs were previously described (Wollscheid et al. 2016). pcDNA CMV-10 3xFlag-OFD1 full length (11012), a (1-276), b (277-663), c (664-1012), and $\Delta$ LIR (mutation of the LIR domain EKYMKI to EKAMKA) were kindly provided by Brunella Franco (TIGEM, Napoli). pEGFP-OFD1 full length (FL) construct was generated by subcloning the OFD1 gene from the pcDNA CMV-10 3xFlagOFD1 construct into the pEGFP_C1 vector with SmaI/BamHI restriction enzymes. pLVX-GFPOFD1 lentiviral construct was generated using the Infusion HD cloning system (Takara Clontech) following manufacturer's instructions. In brief, EGFP-OFD1 sequence was amplified by PCR using primers that anneal on the GFP template and are complementary to pLVX-Puro vector (forward: 5'- CTCAAGCTTCGAATTCATGGTGAGCAAGGGCGAG-3'; reverse: 5'TAGAGTCGCGGGATCCATCAGTTATCTAGATCCGGTGG-3'), followed by EcoRI/BamHI vector linearization and In-fusion reaction. pSLIK-NEO myosin VI shRNA was generated with Gateway $^{\mathrm{TM}}$ LR Clonase ${ }^{\mathrm{TM}}$ II Enzyme mix (ThermoFisher Scientific) by subcloning a nucleotide sequence targeting myosin VI (5'- AGTAATTCAGCACAATATTCCAA - 3') into a pENTR vector, followed by recombination into pSLIK-NEO empty vector.

All the other truncated constructs were engineered by site-directed mutagenesis or recombinant PCR and sequence-verified. Details are available upon request.

\section{Antibodies}

\begin{tabular}{|l|l|l|l|l|}
\hline \multicolumn{5}{|c|}{ Primary antibodies } \\
\hline Epitope & Species & Supplier & Identifier & Application \\
\hline 53BP1 & Rabbit & Abcam & ab36823 & WB 1:1000 \\
\hline Acetylated tubulin & Mouse & Sigma & \#T7451 & IF 1:1000 \\
\hline Acetylated tubulin & Mouse & Sigma & $6-11$ B-1 & IF 1:1000 \\
\hline Centrin1 & Mouse & Millipore & 04-1624 & IF 1:1000 \\
\hline Cep135 & Rabbit & Abcam & ab75005 & IF 1:1000 \\
\hline Cep164 & Goat & Santa-Cruz Biotechnology & sc-240226 & IF 1:700 \\
\hline FLAG & Mouse & Sigma & F3165 & WB 1:5000 \\
\hline GAPDH & Mouse & Santa-Cruz Biotechnology & Sc-32233 & WB 1:5000 \\
\hline GFP & Rabbit & Sigma & G1544 & WB 1:5000
\end{tabular}




\begin{tabular}{|l|l|l|l|l|}
\hline GFP & Mouse & ThermoFisher Scientific & A-11120 & PLA 1:2000 \\
\hline GST & Rabbit & generated in house & & IP \\
\hline LC3 & Rabbit & Cell Signaling & 12741 & WB 1:1000 \\
\hline Myosin VI & Mouse & Sigma & MUD-19 & WB 1:1000 \\
\hline Myosin VI & Rabbit & $\begin{array}{l}\text { generated by EUROGENTEC } \\
\text { S.A., purified by Cogentech }\end{array}$ & 1295 & IP \\
\hline Myosin VI & Rabbit & $\begin{array}{l}\text { generated by EUROGENTEC } \\
\text { S.A., purified by Cogentech }\end{array}$ & 1296 & WB 1:2000; IF 1:400 \\
\hline OFD1 & Rabbit & Sigma & HPA031103 & IF 1:500; PLA 1:2000 \\
\hline OFD1 & Rabbit & $\begin{array}{l}\text { Kindly provided by Brunella } \\
\text { Franco (TIGEM, Napoli) (Giorgio } \\
\text { et al. 2007) }\end{array}$ & & WB 1:100 \\
\hline p21 & Rabbit & Cell Signaling & 2947 & WB 1:1000 \\
\hline p53 (DO-1) & Mouse & Cell Signaling & 18032 & WB 1:1000 \\
\hline p62 & Rabbit & Enzo Lifesciences & BML_PW9860 & WB 1:1000 \\
\hline PCM1 & Mouse & Sigma & SAB1406228 & IF 1:200 \\
\hline Pericentrin & Mouse & Abcam & 28144 & IF 1:200 \\
\hline
\end{tabular}

\begin{tabular}{|l|l|l|l|l|}
\hline \multicolumn{5}{|c|}{ Secondary antibodies } \\
\hline Antibody & Species & Supplier & Catalog number & Application \\
\hline Anti-mouse IgG HRP & Goat & Bio-Rad & 1721011 & WB $1: 5000$ \\
\hline Anti-rabbit IgG HRP & Goat & Bio-Rad & 1706515 & WB $1: 5000$ \\
\hline Anti-mouse Alexa488 & Donkey & ThermoFisher Scientific & A21202 & IF $1: 400$ \\
\hline Anti-mouse Cy3 & Donkey & Jackson Lab & $715-165-150$ & IF $1: 400$ \\
\hline Anti-mouse Alexa488 & Goat & Molecular Probes & A11001 & IF $1: 500$ \\
\hline Anti-rabbit Alexa555 & Donkey & Molecular Probes & A31572 & IF $1: 500$ \\
\hline Anti-rabbit Alexa488 & Donkey & ThermoFisher Scientific & A21206 & IF $1: 400$ \\
\hline Anti-rabbit Cy3 & Donkey & Jackson Lab & $711-165-152$ & IF $1: 400$ \\
\hline Anti-rabbit Alexa647 & Donkey & ThermoFisher Scientific & A31573 & IF $1: 400$ \\
\hline Anti-goat Alexa647 & Donkey & ThermoFisher Scientific & A21447 & IF $1: 400$ \\
\hline
\end{tabular}

Commercial antibodies were validated by the manufacturer. The home-made anti-myosin VI was previously described (Wollscheid et al. 2016).

\section{Cell lines}

hTERT-RPE1 cells (ATCC) were maintained in Dulbecco's Modified Eagle Medium: Nutrient Mixture F-12 (DMEM/F12, Gibco), supplemented with 10\% fetal bovine serum (FBS), 2 mM L- 
glutamine, 0.5 mM Na-Pyruvate, 15mM Hepes pH 7.5. HEK293T (ICLC) and A549 (NCI-60) cells were maintained in DMEM, supplemented with 10\% FBS and $2 \mathrm{mM}$ L-glutamine. hTERT-RPE1 p53 knock-out (KO) and 53BP1 KO were kindly provided by Luca Fava (University of Trento, Trento). In brief, hTERT-RPE1 cells were transduced with Lenti-CRISPR-V2 targeting coding exons of the genes of interest, selected with puromycin, and single clones were characterized through sequencing of the targeted genomic region (Burigotto et al. 2021).

hTERT-RPE1 with stable expression of centrin1-dTomato were kindly provided by Francesca Farina (IRTSV, Grenoble). In brief, hTERT-RPE1 cells were transfected with pdTomato-centrin1 construct (Farina et al. 2016) and selected with geneticin. dTomato-positive cells were selected by fluorescence-activated cell sorting (FACS). To generate the hTERT-RPE1 centrin1-dTomato GFP-OFD1 cell line used for fluorescence recovery after photobleaching (FRAP) experiments, hTERT-RPE1 centrin1-dTomato were transduced with the pLVX-GFP-OFD1 lentiviral construct. Two weeks after transduction, GFP- and dTomato-positive cells were selected by FACS.

To generate A549 myosin VI KO cell line through CRISPR/Cas9, A549 cells were transiently transfected with pD1301-AD vector (prepared by ATUM, atum.bio), containing Cas9, a GFP reporter and a guide RNA (gRNA) targeting exon 2 of myosin VI (gRNA sequence: 5'GTTCAATTGTTAAGCTGTCG-3', designed using ATUM's design tool). GFP-positive cells were FACS-sorted, single cell clones were screened for myosin VI deletion through immunoblot (IB) and IP, and the genomic mutations were characterized by PCR amplification and sequencing of the targeted genomic region. Clone 13S34 that was selected for our experiments have two different mutant alleles: one has an insertion of 2 nucleotides while the other has a deletion of 19 nucleotides. In both cases the frameshift caused stop codons, generating truncated proteins spanning the first 30 or 38 amino acids, respectively.

All cell lines were authenticated by STR profiling (StemElite ID System, Promega) and tested for mycoplasma using PCR and biochemical test (MycoAlert, Lonza).

\section{siRNA transfection, shRNA expression}

Transient knock-downs (KD) were performed using Stealth siRNA oligonucleotides from Thermo Fischer Scientific (Waltham, MA, USA). Cells were transfected twice using RNAiMax (Invitrogen), first in suspension and the following day in adhesion. The following siRNAs were used: 
myosin VI \#1 (when not specified, this siRNA is used to deplete myosin VI):

5'- GAGGCUGCACUAGAUACUUUGCUAA-3'

myosin VI \#2: 5'-GAGCCTTTGCCATGGTACTTAGGTA-3'

OFD1: 5'-GAGAAUGAAGUGUACUGCAAUCCAA-3'

p53: 5'-CCAGUGGUAAUCUACUGGGACGGAA-3'.

hTERT-RPE1 cells with doxycycline-inducible shRNA for myosin VI were generated by transducing the cells with pSLIK-NEO myosin VI shRNA and selection with neomycine. To obtain myosin VI depletion, the expression of the shRNA was induced with $0.5 \mu \mathrm{g} / \mathrm{ml}$ doxycycline for 10 days.

\section{Cell lysis, SDS-PAGE, and immunoblotting (IB)}

Cells were pelleted and the dry pellet was either frozen at $-80^{\circ} \mathrm{C}$ or directly processed. Cell pellets were lysed in JS buffer (50 mM Hepes, pH 7.5, $150 \mathrm{mM} \mathrm{NaCl}, 1.5 \mathrm{mM} \mathrm{MgCl}_{2}, 5 \mathrm{mM}$ EGTA, 10\% glycerol, and 1\% Triton X-100) supplemented with $20 \mathrm{mM}$ sodium pyrophosphate, $\mathrm{pH}$ 7.5, 250 $\mathrm{mM}$ sodium fluoride, $2 \mathrm{mM}$ PMSF, $10 \mathrm{mM}$ sodium orthovanadate, and protease inhibitors (Calbiochem) and incubated for 20 minutes on ice. Lysates were cleared by centrifugation at $15,000 \mathrm{rpm}$ for 20 minutes at $4^{\circ} \mathrm{C}$. Protein concentration was measured by the Bradford assay (Biorad) following the manufacturer's instructions. Proteins were denatured by adding Laemmli Buffer to $1 \mathrm{X}$ and by boiling at $95^{\circ} \mathrm{C}$ for 5 minutes. Proteins were then separated on precast gradient gels (4-20\% TGX precast gel, Bio-Rad) by SDS-PAGE and transferred to nitrocellulose membranes by Transblot Turbo (BIO-RAD). Membranes were blocked for 1 hour (or overnight) in 5\% milk in TBS supplemented with $0.1 \%$ Tween (TBS-T). The primary antibodies were diluted in TBS-T 5\% milk, and incubated onto the membranes for 1 hour at room temperature (RT), or overnight at $4^{\circ} \mathrm{C}$. After washes, the membranes were incubated with the appropriate horseradish peroxidase (HRP)-conjugated anti-mouse or anti-rabbit secondary antibodies (GE Healthcare), subsequently detected with ECL (GE Healthcare). Immunoblots were visualized using films (GE Healthcare).

\section{Protein expression and purification}

GST fusion proteins were expressed in E. coli B121 (DE3) Rosetta at $18^{\circ} \mathrm{C}$ for 16 hours after induction with $0,5 \mathrm{mM}$ IPTG at an $\mathrm{OD}_{600}$ of 0.6. Cell pellets were resuspended in lysis buffer (50 
mM Na-HEPES, pH 7.5, $250 \mathrm{mM} \mathrm{NaCl,} 1 \mathrm{mM}$ EDTA, 5\% Glycerol, 0.1\% NP40, Protease Inhibitor Cocktail set III, Calbiochem, and 0.1 mM PMSF). Sonicated lysates were cleared by centrifugation at 16,000 rpm for 30 minutes. Supernatants were incubated with $1 \mathrm{ml}$ of glutathionesepharose-beads (GE Healthcare) per litre of bacterial culture. After 2 hours at $4^{\circ} \mathrm{C}$, the beads were washed with lysis buffer, high salt buffer (50 mM Tris, pH 8, 1M NaCl, 1 mM EDTA, 1 mM DTT, and $5 \%$ glycerol) and equilibrated in storage buffer $(20 \mathrm{mM}$ Tris, $\mathrm{pH} 8,150 \mathrm{mM} \mathrm{NaCl}, 1 \mathrm{mM}$ EDTA, $1 \mathrm{mM}$ DTT, and 5\% glycerol).

\section{Biochemical experiments}

For co-immunoprecipitation (co-IP) HEK-293T cells were transfected with the indicated constructs. After 48 hours, the cells were lysed in JS buffer and incubated for 20 minutes on ice. Lysates were cleared by centrifugation at $15,000 \mathrm{rpm}$ for 20 minutes at $4^{\circ} \mathrm{C}$. Anti-Flag IP was performed by incubating $1 \mathrm{mg}$ lysate with anti-Flag M2 conjugated beads (Sigma) for 2 hours at $4^{\circ} \mathrm{C}$. For anti-myosin VI IP, $1 \mathrm{mg}$ lysate was incubated with anti-myosin VI antibodies (1295 or 1296) or anti-GST rabbit antibody as negative control. After 2 hours of incubation at $4^{\circ} \mathrm{C}$, protein A sepharose beads were added to the IP and the mixture was incubated for an additional hour. Precipitated immunocomplexes were washed, loaded on a precast gradient gel (4-20\% TGX precast gel, Bio-Rad) and analysed by IB using specific antibodies.

For pull-down experiments, $1 \mu \mathrm{M}$ of GST-fusion proteins immobilised onto GSH beads were incubated for 2 hours at $4^{\circ} \mathrm{C}$ in JS buffer with $500 \mu \mathrm{g}$ of transfected HEK293T cellular lysate. Detection was performed by IB. Ponceau-stained membrane was used to show loading of GSTfusion proteins.

\section{Liquid chromatography-tandem MS (LC-MS/MS) analysis}

To identify myosin VI interactors, anti-myosin VI IP was performed in HeLa, MDA-MB-231, MCF10A, and Caco-2 cells grown in confluent conditions. $3 \mathrm{mg}$ of lysates were incubated with anti-myosin VI antibody (1295) or a rabbit control antibody as negative control. After 2 hours of incubation at $4^{\circ} \mathrm{C}$, protein A sepharose beads were added to the IP and the mixture was incubated for an additional hour. Precipitated immunocomplexes were washed, loaded on a precast gradient gel (4-20\% TGX precast gel, Bio-Rad) and stained with colloidal blue (Colloidal Blue Staining Kit, Invitrogen). 
Slices of interest were cut from gels and trypsinized as previously described by Shevchenko and colleagues (Shevchenko et al. 1996). Peptides were desalted as described by Rappsilber and colleagues (Rappsilber, Ishihama, and Mann 2003), dried in a Speed-Vac and resuspended in 10 $\mu \mathrm{L}$ of solvent A ( $2 \% \mathrm{ACN}, 0.1 \%$ formic acid). $3 \mu \mathrm{L}$ were injected on a quadrupole Orbitrap QExactive mass spectrometer (Thermo Scientific) coupled with an UHPLC Easy-nLC 1000 (Thermo Scientific), with a $25 \mathrm{~cm}$ fused-silica emitter of $75 \mu \mathrm{m}$ inner diameter. Columns were packed in-house with ReproSil-Pur C18-AQ beads (Dr. Maisch Gmbh, Ammerbuch, Germany), $1.9 \mu \mathrm{m}$ of diameter, using a high-pressure bomb loader (Proxeon, Odense, Denmark). Peptide separation was achieved with a linear gradient from 95\% solvent A ( $2 \% \mathrm{ACN}, 0.1 \%$ formic acid) to $40 \%$ solvent B ( $80 \%$ acetonitrile, $0.1 \%$ formic acid) over 30 minutes and from $40 \%$ to $100 \%$ solvent $B$ for 2 minutes at a constant flow rate of $0.25 \mu \mathrm{L} /$ minute, with a single run time of 33 minutes. MS data were acquired using a data-dependent top 12 method, and the survey full scan MS spectra (300-1750 Th) were acquired in the Orbitrap with 70000 resolution, AGC target 1e6, IT 120 ms. For HCD spectra, the resolution was set to 35000, AGC target 1e5, IT 120 ms; 25\% normalised collision energy and isolation width of $3.0 \mathrm{~m} / \mathrm{z}$.

For protein identification, the raw data were processed using Proteome Discoverer (version 1.4.0.288, Thermo Fischer Scientific). MS2 spectra were searched with Mascot engine against uniprot_human_20150401 database (90411 entries), with the following parameters: enzyme Trypsin, maximum missed cleavage 2, fixed modification carbamidomethylation (C), variable modification oxidation (M) and protein N-terminal acetylation, peptide tolerance $10 \mathrm{ppm}, \mathrm{MS} / \mathrm{MS}$ tolerance $20 \mathrm{mmu}$. Peptide Spectral Matches (PSM) were filtered using percolator based on qvalues at a 0.01 FDR (high confidence). Proteins were considered identified with 2 unique high confident peptides (Kall et al. 2007). Scaffold (version Scaffold_4.3.4, Proteome Software Inc., Portland, OR) was used to validate MS/MS based peptide and protein identifications. Peptide identifications were accepted if they could be established at a probability greater than $95.0 \%$ by the Peptide Prophet algorithm (Keller et al. 2002) with Scaffold delta-mass correction. Protein identifications were accepted if they could be established at a probability greater than $99.0 \%$ and contained at least 2 identified peptides. Protein probabilities were assigned by the Protein Prophet algorithm (Nesvizhskii et al. 2003). Proteins that contained similar peptides and that could not be differentiated based on MS/MS analysis alone were grouped to satisfy the principles of parsimony. Proteins sharing significant peptide evidence were grouped into clusters. 


\section{Immunofluorescence (IF)}

Cells were grown on coverslips and fixed with cold $100 \%$ methanol at $-20^{\circ} \mathrm{C}$ for 10 minutes. The coverslips were incubated in PBS with 10\% FBS for 30 minutes for blocking, followed by incubation with primary antibodies (overnight at $4^{\circ} \mathrm{C}$ ) and then secondary antibodies (1 hour at RT) in PBS with 10\% FBS. Incubation with DAPI (Sigma-Aldrich, cat. D9542) for 10 minutes was performed to stain the nuclei. The coverslips were mounted on glass slides using Mowiol Mounting Medium (Calbiochem) or Dako Faramount Aqueous Mounting Medium (s3025, DAKO). Images were acquired using a GE HealthCare Deltavision OMX system, equipped with 2 PCO Edge 5.5 sCMOS cameras, using a 60x 1.42 NA Oil immersion objective, or using a Deltavision Elite system (GE Healthcare) equipped with a IX71 microscope (Olympus), a sCMOS camera, using a 60x PlanApo 1.42 NA oil immersion objective and driven by softWoRx version 7.0.0. Images were acquired as a $\mathrm{z}$-series $(0.2-\mu \mathrm{m} \mathrm{z}$ interval in a range of $4 \mu \mathrm{m})$ and deconvolution was performed using softWorx software. The images are presented as maximum-intensity projections and were prepared using ImageJ (National Institutes of Health).

\section{OFD1, cep164 and PCM1 fluorescence intensity analysis}

For OFD1 and cep164 fluorescence intensity quantifications at the centrioles, hTERT-RPE1 cells were treated with $6 \mu \mathrm{g} / \mathrm{ml}$ nocodazole (M1404, Sigma) for 1 hour to depolymerize the microtubules and thus remove the centriolar satellites. The removal of the satellites is required for the quantification of the centriolar pool of OFD1, which is otherwise indistinguishable from the satellite pool. Z-stack images $(0.2 \mu \mathrm{m}$ intervals $)$ of 20 sections were acquired as detailed above. Centrioles were considered for quantification when paired signals of centrin and OFD1 were observed. The presence cep164 staining was used to identify mother centrioles. Centrioles were excluded from the analysis if residual OFD1 satellite staining was visible in the vicinity of the centrioles. The integrated intensity of a circular 1x $1 \mu \mathrm{m}$ area around the specific OFD1 and cep164 signals were recorded in the sum projected images using ImageJ software (National Institutes of Health). Integrated density was corrected for background intensity signal with the following formula: corrected total fluorescence $=$ integrated density - (area of selected region*mean intensity of background). The number of cells analysed and of experiments performed are detailed in the figure legends. 
For centriolar satellite intensity quantifications, staining of PCM1 was performed in combination with a centriole marker (cep135 or cep164). The centriole marker was used to determine the centre of a circular $3 \times 3 \mu \mathrm{m}$ area, where the PCM1 signals were recorded in the sum projected images. For quantification of OFD1 intensity at the centriolar satellites, OFD1 staining was performed in combination with PCM1 and cep164. In order to exclude the contribution of the centriolar pool of OFD1 from the analysis, OFD1 intensity was recorded only in the area covered by PCM1 in the sum projected images. Corrected total fluorescence was calculated as detailed above.

To induce p53 activation, hTERT-RPE1 cells were incubated with $10 \mu \mathrm{M}$ Nutlin-3 (N6287, Sigma) for 24 hours before fixation and IF.

\section{Statistical analysis}

Statistical analyses were performed with Prism (GraphPad software). Unless differently specified, all the statistical significance calculations were determined using either unpaired Student's T or ANOVA test, or the non-parametric Mann Whitney or Kruskal-Wallis test, after assessing the normal distribution of the sample with Normal (Gaussian) distribution test. Sample sizes are indicated in the figure legends and were chosen arbitrarily with no inclusion and exclusion criteria. The investigators were not blind to the group allocation during the experiments and data analyses.

\section{Proximity ligation assay (PLA)}

For GFP-myosin VI overexpression, hTERT-RPE1 cells were transfected with pEGFP-C1 myosinVI $\mathrm{I}_{\text {short }} \mathrm{FL}$ using Lipofectamine 2000 reagent (Invitrogen), following manufacturer's instruction. Fixation was performed 48 hours after transfection with $100 \% \mathrm{MeOH}$ at $-20^{\circ} \mathrm{C}$ for 10 minutes. The PLA was performed with the Duolink ${ }^{\mathrm{TM}}$ In Situ Orange Starter Kit (Sigma, DUO92102) according to manufacturer's instructions. Primary antibodies used for PLA include mouse anti-GFP (1:2000; ThermoFisher Scientific, A11120) and rabbit anti-OFD1 (1:2000; Sigma, HPA031103). Secondary anti-mouse MINUS and anti-rabbit PLUS probes were used. As negative controls for the PLA signal, the secondary antibodies were used without previous primary antibody incubation or with the single primary antibody. After the PLA procedure, counterstaining with anti-mouse A488 and anti-rabbit A647 was performed to identify GFP-positive cells and to localise OFD1. Confocal microscopy was performed on a Leica TCS SP5 laser confocal scanner mounted on a Leica DMI 6000B inverted microscope equipped with motorised stage. The images 
were acquired with an HCX PL APO 63X/1.4NA oil immersion objective using 405 nm, 488 nm, $568 \mathrm{~nm}$, and $647 \mathrm{~nm}$ laser lines. Leica LAS AF software was used for all acquisitions.

\section{Fluorescence recovery after photobleaching (FRAP)}

hTERT-RPE1 centrin1-dTomato GFP-OFD1 cells were transfected with myosin VI siRNA and plated on MatTek glass bottom dishes (P35G-1.5-14-C, MatTek Life Sciences). FRAP experiments were performed on the UltraVIEW VoX spinning-disk confocal system (PerkinElmer) equipped with an EclipseTi inverted microscope (Nikon), provided with an integrated FRAP PhotoKinesis unit (PerkinElmer), a Hamamatsu CCD camera (C9100-50), a Okolab cage incubator, and driven by Volocity software (Improvision; Perkin Elmer). Photobleaching was achieved on a square region of $3 \times 3 \mu \mathrm{m}$ by using the $488 \mathrm{~nm}$ laser at the maximum output to bleach the GFP signal. Initially, 10 images with a $400 \mathrm{~ms}$ time-frame were acquired to determine the levels of pre-bleach fluorescence. Images were acquired through a $60 \mathrm{X}$ oil-immersion objective (Nikon Plan Apo VC, NA 1.4) with the following time-frame: every second for the first 60 seconds, every 2 seconds for the following 60 seconds and every 5 seconds for the following 120 seconds.

A custom ImageJ macro and a set of functions written in Matlab software were used to analyse the recovery curves. ImageJ was used to measure the mean intensity value over time in the bleached area and the background over time in an area in the field without cells. StackReg ImageJ Plugin was used to align the bleached area over time. The photobleaching recovery curves were then normalised to the pre-bleaching mean intensity values after background correction using Matlab. Matlab was then used to fit the first 150 seconds after photobleaching of the recovery curves with a one phase exponential recovery function with $\mathrm{f}_{0}$ fixed as the first value after photobleaching:

$$
F(t)=A\left(1-e^{-\tau t}\right)+f_{0}
$$

Half maximum time $\left(\mathrm{t}_{1 / 2}\right)$ was then evaluated as:

$$
t 1 / 2=\frac{-\ln (0.5)}{\tau}
$$

and Mobile Fraction as:

$$
\operatorname{MobFr}=\frac{\max (F(t))-\min (F(t))}{1-\min (F(t))}
$$




\section{Structured illumination microscopy (SIM)}

hTERT-RPE1 control and myosin VI-depleted cells were plated on $13 \mathrm{~mm}$ coverslips, thickness $1.5 \mathrm{~mm}$, Boroslicate glass (631-0150, VWR). Four days after transfection, cells were incubated for 1 hour on ice in PBS to induce the depolymerisation of cytoplasmic microtubules, and were subsequently stained with anti-acetylated tubulin and anti-OFD1 antibodies (for more details, IF staining section). SIM Images were acquired using a GE HealthCare Deltavision OMX system, equipped with 2 PCO Edge 5.5 sCMOS cameras, using a 60x 1.42NA Oil immersion objective. Images were deconvolved and reconstructed with Applied Precision's softWorx software. The images are presented as maximum-intensity projections and were prepared using ImageJ (National Institutes of Health).

\section{Primary cilium assay}

hTERT-RPE1 p53 KO cells were transfected with myosin VI or OFD1 siRNAs and plated on coverslips coated with $0.2 \%$ gelatine. Four days after transfection, cells were serum starved in medium with $0 \%$ serum (DMEM/F12 supplemented with $2 \mathrm{mM}$ L-glutamine, $0.5 \mathrm{mM}$ NaPyruvate and $15 \mathrm{mM}$ Hepes, $\mathrm{pH}$ 7.5) for 24 hours to allow cilium assembly. Microtubule depolymerisation was induced by incubating the cells in $\mathrm{PBS}$ at $4{ }^{\circ} \mathrm{C}$ for 1 hour before $\mathrm{Me}-\mathrm{OH}$ fixation. Subsequently, cell lines were stained with DAPI, anti-acetylated tubulin and anti-cep135 primary antibodies. Z-stack images $(0.2 \mu \mathrm{m}$ intervals $)$ of 20 sections were acquired using a Deltavision Elite system (GE Healthcare) equipped with a IX71 microscope (Olympus), a sCMOS camera, using a 60x PlanApo 1.42 NA oil immersion objective and driven by softWoRx version 7.0.0. The number of cells displaying a primary cilium was determined using anti-acetylated tubulin staining, and centrioles were identified through the double cep135/acetylated tubulin staining.

\section{Correlative Light Electron Microscopy (CLEM)}

hTERT-RPE1 cells were transfected with the indicated siRNA 96 hours before fixation and plated on gridded MatTek glass bottom dishes (P35G-1.5-14-CGRD, MatTek Life Sciences). Cells were fixed and stained as described by Mironov \& Beznoussenko (Mironov and Beznoussenko 2013), using anti-pericentrin antibody to identify the position of the centrosomes. Images were acquired 
on a XZ plane to calculate the distance between the glass bottom and the centrosome, using a Leica TCS SP5 laser confocal scanner mounted on a Leica DMI 6000B inverted microscope equipped with a HCX PL APO 63X/1.4NA oil immersion objective using $488 \mathrm{~nm}$ laser line. Leica LAS AF software was used for all acquisitions. Samples were then fixed with $2.5 \% \mathrm{GA}$ in $0.2 \mathrm{M}$ Cacodylate buffer, pH 7.2, and embedded in resin (Beznoussenko and Mironov 2015). The samples embedded in resins were sectioned with diamond knife (Diatome, Switzerland) using Leica EM UC7 ultramicrotome. Sections (50-60 nm) were analysed with a Tecnai 20 High Voltage EM (FEI, The Netherlands) operating at $200 \mathrm{kV}$.

For immunogold staining of myosin VI, A549 wild-type and myosin VI KO cells were plated on gridded MatTek glass bottom dishes and treated as detailed/described above for CLEM. Then, cells were stained with anti-myosin VI 1296 antibody, incubated with Nanogold®-Fab' Goat antiRabbit IgG (\#2004, Nanoprobes). GoldEnhance ${ }^{\mathrm{TM}}$ (EM \#2113, Nanoprobes) was used to enhance the signal from nanogold particles.

\section{Growth curve}

Cells were transfected with the indicated siRNAs. After 24 hours, 10,000 cells were plated on a 6well plate (day 0). From day 3 to 7 after plating, the cells were detached and counted using Beckman Multisizer 3 Coulter Counter. Cell counts were plotted to display the growth curve. During the experiments, the cells were split upon reaching $70 \%$ confluence to avoid slowdown of proliferation due to contact inhibition. Cell dilution was taken into consideration for the total cell count.

\section{Flow cytometry analysis of cell cycle profile}

Myosin VI shRNA expression was induced with $0.5 \mu \mathrm{g} / \mathrm{ml}$ doxycycline for 10 days. The cells were then trypsinized and washed once in PBS. After centrifugation, cell pellets were resuspended in $250 \mu \mathrm{l}$ of $4^{\circ} \mathrm{C}$-cold PBS and fixed by adding $750 \mu \mathrm{l}$ of $100 \%$ Et-OH $\left(-20^{\circ} \mathrm{C}\right)$ dropwise while vortexing. The cells were left in the fixative for 1 hour on ice, washed in PBS-1\% BSA, and resuspended in $1 \mathrm{ml}$ PI $(50 \mu \mathrm{g} / \mathrm{ml})$ and RNAse $(250 \mu \mathrm{g} / \mathrm{ml})$. After incubation at $4^{\circ} \mathrm{C}$ overnight, flow cytometry was performed for cell cycle analysis. Sample acquisition was performed with FACSCanto II (Beckton Dickinson). Analysis of cell cycle distribution was performed with ModFitLT V3.1 software. 


\section{Senescence-associated- $\beta$-galactosidase (SA- $\beta$-gal) assay}

Cells were grown on coverslips, washed in PBS and fixed with 4\% PFA for 10 minutes. Then, the cells were incubated with SA- $\beta$-gal staining solution containing $1 \mathrm{mg} 5$-bromo-4-chloro-3-indolyl beta-D galactopyranoside (X-Gal) per $\mathrm{ml}, 40 \mathrm{mM}$ citric acid/sodium phosphate $\mathrm{pH}$ 6.0, $5 \mathrm{mM}$ potassium ferrocyanide, $5 \mathrm{mM}$ potassium ferricyanide, $150 \mathrm{mM} \mathrm{NaCl}$, and $2 \mathrm{mM} \mathrm{MgCl} 2$. After incubation at $37^{\circ} \mathrm{C}$ overnight, the cells were washed with PBS and mounted on glass slides using Mowiol Mounting Medium. Images were acquired using a digital camera connected to a whitelight microscope. SA- $\beta$-gal activity was detected in senescent cells as local perinuclear blue precipitate. 